\title{
Upgrading the fuel properties of hydrochar by co-hydrothermal carbonisation of dairy manure and Japanese larch (Larix kaempferi): product characterisation, thermal behaviour, kinetics and thermodynamic properties
}

\author{
Mohammed Aliyu ${ }^{1,2} \cdot$ Kazunori Iwabuchi ${ }^{3}$ (i) Takanori Itoh $^{4}$
}

Received: 20 July 2021 / Revised: 9 October 2021 / Accepted: 19 October 2021

(C) The Author(s) 2021

\begin{abstract}
This study investigated co-hydrothermal carbonisation (co-HTC) of dairy manure (DM) and wood shavings from Larix kaempferi, commonly known as the Japanese larch (JL) to enhance the fuel properties of the resulting hydrochar. The JL was mixed with the DM at 25,50 and $75 \mathrm{wt} . \%$ ratios. Co-HTC was conducted at $260{ }^{\circ} \mathrm{C}$ for $20 \mathrm{~min}$. The resulting hydrochars were characterised based on the physicochemical properties and the thermal behaviour. Results showed that the hydrochar solid biofuel properties improved as the ratio of JL was increased. The produced hydrochars were in the region of lignite and closed to the region of the coal with increased fixed carbon, carbon contents and lowered H/C and O/C ratios. Hydrochar with ash content of $7.2 \pm 0.5 \%$ was obtained at $75 \mathrm{wt} . \% \mathrm{JL}$. In addition, the HHV of hydrochar increased remarkably to $26.4 \pm 0.02 \mathrm{MJ} / \mathrm{kg}$ as the mass ratio of the JL was increased. The surface morphology of the hydrochars were altered and became distinct while the specific surface area (SSA) and the total pore volume (TPV) of the hydrochars increased at increasing the mass ratio of the JL. The surface functional groups were also altered by the co-HTC process. A decline in the combustion performance was observed after the HTC process but improved at $75 \mathrm{wt} \% \mathrm{JL}$ after the co-HTC process. The kinetic analysis also revealed that the activation energy decreased after the HTC process but increased to a higher value at $50 \mathrm{wt}$ \% JL after the co-HTC process. Therefore, hydrochar production by co-HTC of DM and JL has proved to be an effective and promising solid biofuel source.
\end{abstract}

Keywords Japanese larch · Dairy manure · Thermochemical conversion · Co-hydrothermal carbonisation · Hydrochar . Solid biofuel

\section{Introduction}

The fast depletion of fossil fuel reserves across the world and subsequent environmental pollution such as the greenhouse gas emission has made biomass an attractive source of energy [1,2]. Waste biomass such as animal manure is increasingly gaining attention due to the fast-growing animal husbandry across the world [3]. For this reason, animal manure generation have been reported in billions of tons in some countries annually [3, 4]. In Hokkaido prefecture of Japan alone, about 20 million tons of animal manure is generated annually [5]. Hence, biomass from animal manure could become one of the sustainable sources of biofuel production [3, 6]. However, there are limitations to the use of animal manure as a combustion feedstock due to its high moisture content, high ash 
content, poor grindability, and low energy density which can result in low combustion efficiency $[3,7]$. To overcome some of these aforementioned drawbacks, it is necessary to pretreat animal manure to improve its fuel property. One of the pretreatment techniques that is used to upgrade the fuel property of animal manure is hydrothermal carbonisation (HTC) $[3,6,8]$.

HTC is an effective technique to carbonise and improve the fuel property of animal manure as a solid biofuel source $[3,6]$. The conversion process uses hot compressed fluid at a moderate temperature range of 180 to $260{ }^{\circ} \mathrm{C}$ in an autoclave reactor $[2,7]$. Unlike other available thermal conversion technologies for biomass, HTC does not need the predrying of a feedstock before carbonisation [2], and therefore, appropriate to convert high moisture content animal manure to solid biofuel. However, animal manure is recognised as a high ash content feedstock after HTC pre-treatment $[4,6$, 9, 10]. For instance, Wu et al. [6] and Gao et al. [9] reported ash contents of $39.48 \mathrm{wt} . \%$ and $40.66 \mathrm{wt}$ \% with higher heating values (HHV) of 17.86 and $19.88 \mathrm{MJ} / \mathrm{kg}$ in hydrochar after HTC treatment of dairy manure (DM) at $260{ }^{\circ} \mathrm{C}$. Reza et al. [10] also reported an ash content of $25.36 \mathrm{wt} . \%$ and a HHV of $22.1 \mathrm{MJ} / \mathrm{kg}$ after the HTC pre-treatment of cow manure at $260{ }^{\circ} \mathrm{C}$. These high ash contents of the carbonised solid biofuel from animal manure mentioned above could result in severe ash related problems such as fouling and scaling deposits if directly used for combustion. Consequently, this can lead to a reduction in the available area for heat transfer in a furnace and some connecting sections of combustion equipment [11]. It is, therefore, imperative to consider a technique that could further help to improve the fuel property and reduce the ash content in animal manure for efficient utilisation as a solid biofuel.

Co-hydrothermal carbonisation (co-HTC) of animal manure and a lignocellulosic biomass is a promising technique for the production of hydrochar with high energy recovery and low ash content [6]. In co-HTC, two or more feedstocks with distinct properties are mixed and carbonised to improve the fuel properties of the composite [12-15]. At present, several studies have reported a co-HTC of lignocellulosic biomass with other feedstocks such as coal, sewage sludge, medical waste, iron sludge, food waste and polyvinyl chloride [16]. However, limited study is available on the co-HTC of animal manure and lignocellulosic biomass. To the authors knowledge, only a co-HTC of swine manure and lignocellulosic biomass have been reported to date [3, 17]. Owing to the heterogeneous and different biochemical properties of animal manure, co-HTC of DM and wood shavings from Larix kaempferi, commonly known as the Japanese larch (JL), would provide additional insight into the synergistic effect of the co-HTC process on the resulting solid biofuel. The $\mathrm{JL}$ is a potential biofuel source that is generated as wood shavings during wood processing, and it is recognised as a low ash content lignocellulosic biomass thus may result in a positive synergistic effect with the DM [18].

Synergistic effect in co-HTC refers to the consequences of the interaction between the composite raw feedstocks which can result in a positive or a negative effect. If the total value of observed property after the co-HTC process is more than the total values for the individual feedstocks, it is considered a positive synergistic effect while the opposite is considered a negative effect [16]. Hence, the co-HTC of these two distinct biomasses may produce hydrochar of notable quality and affect the structural and functional groups inherent in the individual hydrochars. Also, the data obtained could provide some useful insights during the design of combustion equipment.

To design a combustion equipment at an industrial scale, it is necessary to understand the combustion behaviour, kinetics and thermodynamic properties of a solid biofuel. To achieve this, isoconversional model-free kinetics is sometimes employed by using the data generated from thermogravimetric analysis (TGA) [3, 19]. Isoconversional model-free kinetics such as the Flynn-Wall-Ozawa (FWO) and Kissinger-Akahira-Sunose (KAS) are useful methods for determining the kinetic parameters of biomass decomposition, based on the data obtained from TGA $[19,20]$. However, no available published data on the combustion behaviour, kinetic and thermodynamic properties of hydrochar from the co-HTC of DM and JL at varying mass ratios have been reported. Hence, the objective of this study was to investigate the changes in the fuel properties, structural morphology, functional group, and combustion characteristics of hydrochar from the co-HTC of JL and DM.

\section{Materials and methods}

\subsection{Materials}

DM was obtained from an experimental farm of Field Science Centre for Northern Biosphere, Hokkaido University, Japan. For experimental purposes, the DM sample was dried in an electric oven for $24 \mathrm{~h}$ at $105^{\circ} \mathrm{C}$ to a constant mass. The JL wood shavings were obtained from the wood engineering laboratory of Hokkaido University, Japan, and were also dried to a constant mass. The dried samples were milled using a portable electric milling machine to ensure thorough mixing in ratios. The $\mathrm{JL}$ wood shavings were mixed in mass ratios with the DM at 25, 50 and $75 \mathrm{wt} . \%$. The prepared samples were sealed in plastic bags and stored before the co-HTC experiment as shown in the supplementary file (S1). 


\subsection{HTC reactor setup and procedure}

Co-HTC experiments were performed in a $70-\mathrm{mL}$ stainless steel batch reactor TVS-N2 (Taiatsu Techno, Tokyo, Japan) with a temperature and pressure limits of $300{ }^{\circ} \mathrm{C}$ and $8 \mathrm{MPa}$. For each batch of the experiment, $20 \pm 0.01 \mathrm{~g}$ of oven-dried sample and distilled water were well mixed and placed in the reactor. The reactor was sealed, and oxygen was swept out from the sealed reactor by flushing with pure nitrogen gas thrice. The reactor's temperature was controlled by a PID (proportional-integral-derivative) to the desired HTC temperature. A reaction temperature of $260{ }^{\circ} \mathrm{C}$ was used while reaction time at peak temperature was kept for $20 \mathrm{~min}$ for all the experiments. A reaction temperature of $260{ }^{\circ} \mathrm{C}$ was chosen because it is considered an appropriate temperature to produce hydrochar of a coallike properties [2]. Holding time of $20 \mathrm{~min}$ at peak temperature was used to minimise a further mass loss [21-23].

After terminating the reaction, the reactor was placed in cold water for rapid cooling. The pressure release valve was opened, and the gaseous products were vented into a fume hood. The solid hydrochar was recovered from the reactor and weighed. The recovered hydrochar was dried in an electric oven at $105{ }^{\circ} \mathrm{C}$ for $24 \mathrm{~h}$. The dried hydrochar was milled, sieved, and stored in sample bottles for analyses. The produced hydrochars were named $100 \mathrm{wt} . \%$ DM, 25 wt.\% JL, 50 wt.\% JL, 75 wt.\% JL and 100 wt.\% JL. Each batch of the experiment was conducted thrice with the respective means recorded with standard deviations.

\subsection{Properties and analytical determination}

The mass yield of hydrochar (MY), the energy densification ratio (EDR), and the energy yield (EY) were calculated using Eqs. (1) to (3) [12, 24]. The calorific values were determined using an OSK 200 bomb calorimeter (Ogawa Sampling, Saitama, Japan) by combusting at least $0.5 \mathrm{~g}$ of each sample in a calorimeter with oxygen at $0.3 \mathrm{MPa}$ [25].

$$
\begin{aligned}
& M Y=(\%)=\frac{m_{\mathrm{hc}}}{m_{\mathrm{f}}} \times 100 \\
& E D R=\frac{H H V_{\mathrm{hc}}}{H H V_{\mathrm{f}}} \\
& E Y(\%)=\left[M Y \times\left(\frac{H H V_{h c}}{H H V_{\mathrm{f}}}\right)\right] \times 100
\end{aligned}
$$

where $m_{\mathrm{hc}}(\mathrm{g})$ is the dry mass of the hydrochar, $m_{\mathrm{f}}(\mathrm{g})$ is the dry mass of the raw feedstock, and $H H V_{\mathrm{hc}}(\mathrm{MJ} / \mathrm{kg})$ and $H H V_{\mathrm{f}}(\mathrm{MJ} / \mathrm{kg})$ are the higher heating values of the hydrochar and raw feedstock.

The ash contents of the samples were determined using an electric muffle furnace (ADVANTEC, FUL220FA, Japan) by incinerating $1 \mathrm{~g}$ at $600{ }^{\circ} \mathrm{C}$ for $3 \mathrm{~h}$. The volatile matter (VM) was determined using ASTM standard procedure (E872) by heating the samples at $950{ }^{\circ} \mathrm{C}$ for $7 \mathrm{~min}$ in an electric furnace. Then, the fixed carbon (FC [\%] = 100-VM [\%] - ash $[\%])$ and the fuel ratio $(\mathrm{FR}=\mathrm{FC} / \mathrm{VM})$ were calculated.

The carbon, hydrogen and nitrogen $(\mathrm{C}, \mathrm{H}$ and $\mathrm{N})$ contents in the samples were determined using an elemental analyser (Exeter Analytical, North Chelmsford, MA, USA), and the oxygen content was calculated by difference $(\mathrm{O}$ $[\%]=100-\mathrm{C}[\%]-\mathrm{H}[\%]-\mathrm{N}[\%]-$ ash $[\%])$. The carbon retention (CR) was calculated using Eq. (4).

$C R(\%)=\left(\frac{C_{\mathrm{h} c}}{C_{\mathrm{f}}}\right) \times M Y$

where $C_{\mathrm{hc}}$ and $C_{\mathrm{f}}$ are the wt. $\%$ of carbon in hydrochar and the raw sample, respectively. Note that $C_{\mathrm{f}}$ is also the wt.\% of carbon in the raw mixtures. The raw mixtures were thoroughly mixed in mass ratios, milled and the ultimate compositions were determined using an elemental analyser as well.

The surface morphology of the raw samples and the hydrochars were captured using an SEM (Scanning Electron Microscopy) analyser (JEOL JSM-7001FA, USA) at $15 \mathrm{kV}$ and a working distance of $10 \mathrm{~mm}$. Furthermore, to elucidate the changes in the surface characteristics and for potential usage in soil amendment and adsorption of contaminants in aqueous solutions, the Brunauer-Emmett-Teller (BET) specific surface area (SSA), total pore volume (TPV) and average pore diameter (APD) were determined by BelsorpII mini. The Fourier transform infrared spectroscopy (FTIR) was performed using JASCO IRT-3000 N spectrometer with attenuated total reference (ATR) accessory. FTIR spectra from 128 scan were recorded in the wavenumber range of 4000 to $500 \mathrm{~cm}^{-1}$ with a $4 \mathrm{~cm}^{-1}$ resolution.

\subsection{Thermal analysis}

To observe the combustion behaviour of the hydrochars at different heating rates, a combustion experiment was performed in a thermal analyser (TGA/DSC $3^{+}$, METTLER TOLEDO, USA) under an air atmosphere. To eliminate heat and mass transfer limitation within the sample, about $25 \mathrm{mg}$ of sample was placed in a $150 \mu \mathrm{L}$ aluminium oxide $\left(\mathrm{Al}_{2} \mathrm{O}_{3}\right)$ crucible. The sample was heated from the room temperature to $900{ }^{\circ} \mathrm{C}$ with an airflow rate of $100 \mathrm{~mL} / \mathrm{min}$ at the heating rates of $5,10,15$ and $20^{\circ} \mathrm{C} / \mathrm{min}$. For each sample, the TGA experiment was repeated at least twice for accuracy. The thermogravimetric (TG) and differential thermogravimetric (DTG) data were used to determine some characteristic temperatures 
and combustion parameters which include the ignition temperature $\left(\mathrm{I}_{\mathrm{T}}\right)$, the burnout temperature $\left(\mathrm{B}_{\mathrm{T}}\right)$, the temperature at maximum decomposition $\left(\mathrm{T}_{\mathrm{m}}\right)$, the burnout time $\left(\mathrm{B}_{\mathrm{t}}\right)$, the residual mass $\left(\mathrm{R}_{\mathrm{m}}\right)$, the maximum mass loss rate $\left(\mathrm{DTG}_{\max }\right)$ and the average mass loss rate $\left(\mathrm{DTG}_{\mathrm{av}}\right)$. The $\mathrm{I}_{\mathrm{T}}\left({ }^{\circ} \mathrm{C}\right)$ indicates the temperature at which the fuel starts to burn while $\mathrm{B}_{\mathrm{T}}\left({ }^{\circ} \mathrm{C}\right)$ denotes the temperature for the complete combustion of the fuel and were determined by the TG-DTG tangent method $[3,26]$. The $\mathrm{T}_{\mathrm{m}}\left({ }^{\circ} \mathrm{C}\right)$ is the temperature at the maximum mass loss rate (DTG) or the peak temperature. The $\mathrm{R}_{\mathrm{m}}(\%)$ is the percentage of the residue left after complete combustion of the sample. Furthermore, to evaluate the combustion performance of the raw samples and the hydrochars, the comprehensive combustion index (CCI) and combustion stability index (CSI) were calculated using Eqs. (5) and (6), respectively [3, 27-29].

$C C I=\frac{D T G_{\max } \times D T G_{a v}}{I_{T}^{2} \times B_{T}}$

$C S I=8.5875 \times 10^{7} \times \frac{D T G_{\max }}{I_{T} \times T_{m}}$

\subsubsection{Kinetics and thermodynamic properties of activation}

To determine the activation energy through TGA, more than one heating rate is required to plot a regression line $[3,20]$. The heating rates of $5,10,15$ and $20{ }^{\circ} \mathrm{C} / \mathrm{min}$ were used to study the combustion kinetics of the raw samples and the hydrochars using non-isothermal isoconversional model-free methods. These methods were applied to convert the mass loss data obtained by TGA analysis into the conversion rate $(\alpha)$ as shown in Eq. (7), while the activation energies were calculated using the Flynn-Wall-Ozawa (FWO) and Kissinger-Akahira-Sunose (KAS) methods using Eqs. (8) and (9), respectively. The thermodynamic properties namely, the pre-exponential factor $(A)$, Gibbs free activation energy $\left(\Delta G^{\ddagger}\right)$, enthalpy of activation $\left(\Delta H^{\ddagger}\right)$ and the entropy of activation $\left(\Delta S^{\ddagger}\right)$ were determined using Eqs. (10) to $(13)$ [3, 30].

$\alpha=\frac{m_{0}-m}{m_{0}-m_{f}}$

$\ln \beta=\ln \frac{A E_{a}}{R G(\alpha)}-5.331-1.052 \frac{E_{a}}{R T}$

$\ln \left(\frac{\beta}{T^{2}}\right)=\ln \left(\frac{A R}{E_{a} G(\alpha)}\right)-\frac{E_{a}}{R T}$

$A=\frac{\beta E_{a} e^{\frac{E_{a}}{R T_{m}}}}{R T_{m}^{2}}$
$\Delta G^{\ddagger}=E_{a}+R T_{m} \ln \left(\frac{k_{B} T_{m}}{h A}\right)$

$\Delta H^{\ddagger}=E_{a}-R T_{m}$

$\Delta S^{\ddagger}=\frac{\Delta H^{\ddagger}-\Delta G^{\ddagger}}{T_{m}}$

Here, $\alpha$ is the conversion rate, $m_{0}$ is the initial mass (mg), $m$ is the actual mass, $m_{f}$ is the final mass, $A\left(\mathrm{~s}^{-1}\right)$ is a preexponential factor, $R$ is the universal gas constant $8.314 \mathrm{~J} \mathrm{~K}^{-1} \mathrm{~mol}^{-1}, G(\alpha)$ is the mechanism function and $T$ is the absolute temperature $(\mathrm{K})$ and $\mathrm{T}_{\mathrm{m}}$ is the temperature at maximum mass loss rate, $h$ is the Planck's constant $(6.63 \times$ $\left.10^{-34} \mathrm{~m}^{2} \mathrm{~kg} \mathrm{~s}^{-1}\right), k_{\mathrm{B}}$ is the Boltzmann constant $\left(6.63 \times 10^{-23}\right.$ $\left.\mathrm{m}^{2} \mathrm{~kg} \mathrm{~s}^{-2}\right), \ln \beta$ or $\ln \left(\frac{\beta}{T^{2}}\right)$ versus $1 / \mathrm{T}$ was plotted as a straight line at the different heating rates $(\beta)$ of $5,10,15$ and $20^{\circ} \mathrm{C} /$ $\min$. The activation energies $\left(E_{a}\right)$ were calculated for each $\alpha$ from the slope of the regression lines of $\ln \beta$ versus $1 / \mathrm{T}$ for FWO and $\ln \left(\frac{\beta}{T^{2}}\right)$ versus $1 /$ T for KAS.

\section{Results and discussion}

\subsection{Hydrochar yield}

The MY of hydrochars at the different mixed ratios is shown in Table 1. The MY slightly decreases with increasing proportion of the JL. The highest MY of $61.5 \pm 2.5 \%$ was observed at $25 \mathrm{wt} . \% \mathrm{JL}$. The decreasing MY as a result of increasing wt.\% of the JL could be attributed to the decreasing ash content (Table 1). Ash is reported to be an inert material that does not participate in HTC reactions, hence decreasing ash content of the co-HTC process may have contributed to the decreasing MY [12]. A similar observation was reported by He et al. [12] where the increasing proportion of rice straw ratio to sewage sludge decreases the MY of hydrochar and was attributed to the decreasing ash content.

\subsection{Proximate and ultimate properties of the hydrochars}

The proximate and the ultimate properties of the raw samples and the hydrochars are presented in Table 1. The VM of the hydrochars were significantly lowered after the conversion process. The results indicated that the VM may have been converted to other substances during the process, such as liquid or gaseous products [31]. The FC is one of the quality indices of a solid biofuel. The FC for the hydrochar $100 \mathrm{wt} . \% \mathrm{DM}$ was $30.1 \pm 0.9 \%$ and increased remarkably to $47.3 \pm 0.6 \%$ after co-HTC with the JL. The increased FC at 
Table 1 Mass yield, proximate, ultimate, (wt.\%) and energy properties of the hydrochars at $260{ }^{\circ} \mathrm{C}$

\begin{tabular}{|c|c|c|c|c|c|c|c|}
\hline Parameters & Raw DM & Raw JL & 100 wt.\% DM & 25 wt.\% JL & $50 \mathrm{wt} . \% \mathrm{JL}$ & 75 wt.\% JL & 100 wt. \% JL \\
\hline MY(\%) & - & - & $59.7 \pm 3.4$ & $61.5 \pm 2.5$ & $59.2 \pm 1.5$ & $58.9 \pm 3.9$ & $59.1 \pm 2.8$ \\
\hline \multicolumn{8}{|c|}{ Proximate properties } \\
\hline VM (\%) & $65.1 \pm 0.3$ & $85.8 \pm 0.3$ & $43.9 \pm 0.5$ & $46.1 \pm 0.5$ & $44.5 \pm 0.1$ & $45.5 \pm 0.1$ & $51.8 \pm 0.6$ \\
\hline $\mathrm{FC}^{*}(\%)$ & $15.9 \pm 0.6$ & $14.2 \pm 0.3$ & $30.1 \pm 0.9$ & $32.4 \pm 0.4$ & $42.5 \pm 0.3$ & $47.3 \pm 0.6$ & $47.6 \pm 0.2$ \\
\hline Ash (\%) & $18.9 \pm 0.4$ & $0.08 \pm 0.1$ & $25.9 \pm 0.8$ & $21.5 \pm 0.6$ & $13.0 \pm 0.6$ & $7.2 \pm 0.5$ & $0.59 \pm 0.5$ \\
\hline FR & $0.25 \pm 0.01$ & $0.29 \pm 0.01$ & $0.68 \pm 0.03$ & $0.70 \pm 0.01$ & $0.95 \pm 0.1$ & $1.0 \pm 0.01$ & $0.92 \pm 0.01$ \\
\hline \multicolumn{8}{|c|}{ Ultimate properties } \\
\hline $\mathrm{C}(\%)$ & $41.6 \pm 0.3$ & $49.7 \pm 0.1$ & $51.9 \pm 0.1$ & $55.3 \pm 0.4$ & $62.3 \pm 0.3$ & $65.0 \pm 0.2$ & $67.9 \pm 0.3$ \\
\hline $\mathrm{H}(\%)$ & $5.1 \pm 0.04$ & $5.9 \pm 0.07$ & $4.6 \pm 0.02$ & $4.6 \pm 0.04$ & $4.7 \pm 0.01$ & $4.7 \pm 0.04$ & $4.8 \pm 0.03$ \\
\hline $\mathrm{N}(\%)$ & $2.1 \pm 0.00$ & $0.3 \pm 0.1$ & $2.9 \pm 0.00$ & $2.3 \pm 0.00$ & $1.6 \pm 0.00$ & $0.84 \pm 0.00$ & $0.30 \pm 0.00$ \\
\hline $\mathrm{O} *(\%)$ & $32.3 \pm 0.3$ & $44.0 \pm 0.1$ & $14.7 \pm 0.1$ & $16.4 \pm 0.4$ & $18.4 \pm 0.3$ & $22.3 \pm 0.2$ & $26.4 \pm 0.3$ \\
\hline $\mathrm{CR}(\%)$ & - & - & $73.9 \pm 4.8$ & $74.3 \pm 6.9$ & $83.0 \pm 1.8$ & $84.5 \pm 3.4$ & $81.7 \pm 3.3$ \\
\hline \multicolumn{8}{|c|}{ Energy properties } \\
\hline HHV (MJ/kg) & $16.9 \pm 0.03$ & $18.8 \pm 1.5$ & $21.9 \pm 0.08$ & $22.9 \pm 0.05$ & $25.1 \pm 0.02$ & $26.4 \pm 0.02$ & $27.4 \pm 0.1$ \\
\hline EDR & - & - & $1.29 \pm 0.01$ & $1.31 \pm 0.03$ & $1.40 \pm 0.08$ & $1.44 \pm 0.12$ & $1.45 \pm 0.12$ \\
\hline $\mathrm{EY}(\%)$ & - & - & $77.4 \pm 0.08$ & $80.8 \pm 0.05$ & $82.9 \pm 0.02$ & $84.9 \pm 0.02$ & $85.9 \pm 0.1$ \\
\hline
\end{tabular}

${ }^{*}$ Calculated by difference

increasing wt.\% of JL is likely due to the decreasing ash content for the co-HTC process. The FC for the $100 \mathrm{wt} . \% \mathrm{JL}$ and $75 \mathrm{wt} \%$ JL became almost equal in value after the co-HTC process. This indicates that the co-HTC of DM and JL is an effective technique to produce hydrochar with improved fuel properties. He et al. [12] and Zhang et al. [24] reported similar observations for the co-HTC of sewage sludge/rice straw and corn stalk/swine manure, respectively. The ash content of the hydrochar decreased as the wt.\% of the JL was increased due to the lower ash property of the JL. The ash content of 100 wt. $\%$ DM hydrochar was $25.9 \pm 0.8 \%$, but after co-HTC, hydrochar of a lower ash content of $7.2 \pm 0.5 \%$ was obtained at $75 \mathrm{wt} . \% \mathrm{JL}$. The difference in the ash content of $75 \mathrm{wt} . \% \mathrm{JL}$ and $100 \mathrm{wt} \% \mathrm{DM}$ amounts to $72.1 \%$, suggesting that the JL is an effective feedstock to improve the fuel properties of a high ash feedstock such as the DM. This could reduce ash related problems such as fouling and slagging if used in a combustion equipment. A similar observation was also reported by Lang et al. [17] where the increase in the proportion of cornstalk ratio to swine manure produced hydrochar with an ash content of $8.17 \pm 0.25 \%$.

The FR can be used to rank hydrochar as a coal-like solid fuel [32]. The FR of the hydrochars is shown in Table 1. After co-HTC, FR of the hydrochars increased as the blending ratio of the JL in the mixture was increased. The observed increase could be attributed to the increasing FC, relative to the VM. The highest FR of $1.0 \pm 0.01$ observed at $75 \mathrm{wt} . \% \mathrm{JL}$ showed that the increased wt.\% of the JL has improved the fuel property of the hydrochar after the co-HTC process and hence a positive synergy. It was also observed that the FR of the hydrochars were higher than 0.6 reported for lignite and very close to 1.2 reported for a subbituminous coal [12, 33].

The carbon content of the hydrochars increased after the HTC and co-HTC pre-treatments. The observed increase in the carbon content was due to the dehydration and decarboxylation reactions during the conversion process [34]. Furthermore, increasing the proportion of JL significantly increases the carbon content of the hydrochars. The increased carbon content could be related to the higher carbon content of the JL which may have augmented the carbon content of the hydrochars from the co-HTC process. Hence, the carbon content improved to $65.0 \pm 0.2 \%$ at 75 wt.\% JL after the co-HTC process. The hydrogen content of the hydrochars decreased compared to the raw feedstocks likely due to dehydration reaction during conversion [2]. However, the hydrogen content of the hydrochars remained almost the same at increasing wt.\% of the JL possibly owing to the use of the same reaction severity (same production temperature of $260{ }^{\circ} \mathrm{C}$ ). The nitrogen content of the 100 wt.\% DM increased from 2.1 to $2.9 \%$, this is consistent with the study by Reza et al. [10] where the increased nitrogen content in hydrochar from cow manure after HTC pre-treatment at $260{ }^{\circ} \mathrm{C}$ was attributed to the adsorption of degraded nitrogen from protein in cow manure at higher HTC temperature. Thereafter, the nitrogen content decreased from 2.9 to $0.84 \%$ as the proportion of JL was increased. This could be attributed to the lower nitrogen content of the JL with a higher proportion of JL lowering the nitrogen content of the hydrochars from the co-HTC process. Decreased oxygen content was observed in the hydrochars at the different blend ratios after the conversion of the raw samples. The 
removal of oxygen from the raw samples is very important to increase the energy density [6]. The removal of oxygen was due to dehydration and decarboxylation reactions during the conversion process $[9,31,35]$. However, the oxygen content of the hydrochars increases as the wt.\% of JL was increased. This could be attributed to the higher oxygen content in the raw JL (Table 1) which may have contributed to the increased oxygen contents of the hydrochars from the coHTC process. The results of the calculated carbon retention are presented in Table 1. The CR was enhanced to $84.5 \pm 3.4$ at $75 \mathrm{wt} . \% \mathrm{JL}$. This showed that the co-HTC treatment of $\mathrm{JL}$ and DM was an effective for carbon retention in a solid biofuel.

\subsection{HHV, energy densification ratio and energy yield of the hydrochars}

The HHV of the hydrochars increases remarkably as the ratio of the JL was increased (Table 1). The co-HTC process enhanced the HHV to $26.4 \pm 0.02 \mathrm{MJ} / \mathrm{kg}$. This enhancement in the HHV was not surprising, considering the initial higher HHV of the JL. The improvement in the HHV of the hydrochars after co-HTC may have been partly contributed by the higher carbon and lower ash contents of the JL. The improved HHV reported in this study suggested that the coHTC of DM and JL was effective in upgrading the energy property of hydrochar as a solid biofuel. He et al. [12], Wang et al. [36] and Ma et al. [37] reported a similar trend for sewage sludge/rice straw, food waste/woody biomass, and sewage sludge/sawdust co-HTC, respectively. The EDR was calculated to evaluate the degree of energy densification after the conversion process. Expectedly, the EDR showed a similar trend to that of the HHV, with a maximum EDR of 1.44 observed at $75 \mathrm{wt} \% \mathrm{JL}$ after the co-HTC process. The EY also slightly increased progressively as the mass ratio of the JL was increased. The EY improved to $84.9 \pm 0.02 \%$ (Table 1). The EY was not expected to change significantly because it is dependent on the MY which did not change significantly as well.

\section{4 van Krevelen diagram for the raw samples and the hydrochars}

To elucidate the changes in the atomic ratios of the raw biomass and the hydrochars, data from elemental analyses was used to plot the van Krevelen diagram. The van Krevelen diagram can provide some insight into the type and quality of fuel and the reflection in the alteration of biomass composition. A fuel with a lower $\mathrm{O} / \mathrm{C}$ and $\mathrm{H} / \mathrm{C}$ atomic ratio is highly preferred due to its decreased smoke, water vapour and energy losses experienced during combustion [38-40]. To explain the changes in the atomic ratio composition of raw samples and the produced hydrochars, the atomic ratios of $\mathrm{H} / \mathrm{C}$ and $\mathrm{O} / \mathrm{C}$ were calculated and plotted in a van Krevelen diagram using the data from elemental analysis (Fig. 1). In this diagram, the atomic ratios of $\mathrm{H} / \mathrm{C}$ and $\mathrm{O} / \mathrm{C}$ moved from the top right to the bottom left-hand corner after the conversion process. The decreased $\mathrm{H} / \mathrm{C}$ and $\mathrm{O} / \mathrm{C}$ ratios suggested increased aromatisation or coalification degree, which can be beneficial for carbon sequestration [24, 41]. Figure 1 shows that aromatisation or coalification degree of the produced hydrochars from the co-HTC process was enhanced. A similar observation was reported for sewage sludge and pinewood sawdust from co-HTC by Zhang et al. [24]. The hydrochars fell within the region of lignite and closed to the coal region. Therefore, the hydrochars can be used for pulverised coal injection in a furnace for co-combustion with coal since they matched some atomic ratios close to those of a coal [42].

\subsection{Surface morphology of the raw and hydrochar samples}

To observe the changes in the surface morphology of the hydrochars after alteration by HTC and the co-HTC processes, SEM images were captured. The SEM images (Fig. 2) showed that the surface morphology of the hydrochars was altered after the HTC and the co-HTC processes. Increasing the wt.\% of JL appeared to have a co-HTC effect on the surface morphology of the hydrochars (Fig. 2d-f) with distinct surfaces. The increasing SSA (Fig. 3) due to the increasing wt.\% of the JL and the change in feedstock compositions could be a contributing factor for the observed different surface morphology of the hydrochars. Notably, the $100 \mathrm{wt} . \% \mathrm{JL}$ revealed the appearance of some visible porous pores likely due to its high SSA. These pores disappeared due to the co-HTC with the DM. The introduction of DM

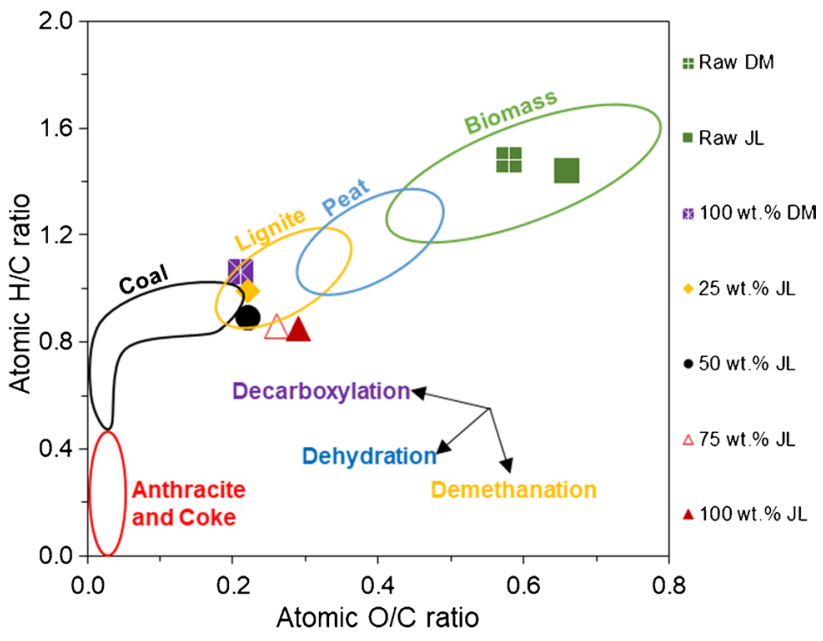

Fig. 1 The van Krevelen diagram for the raw samples and the hydrochars 

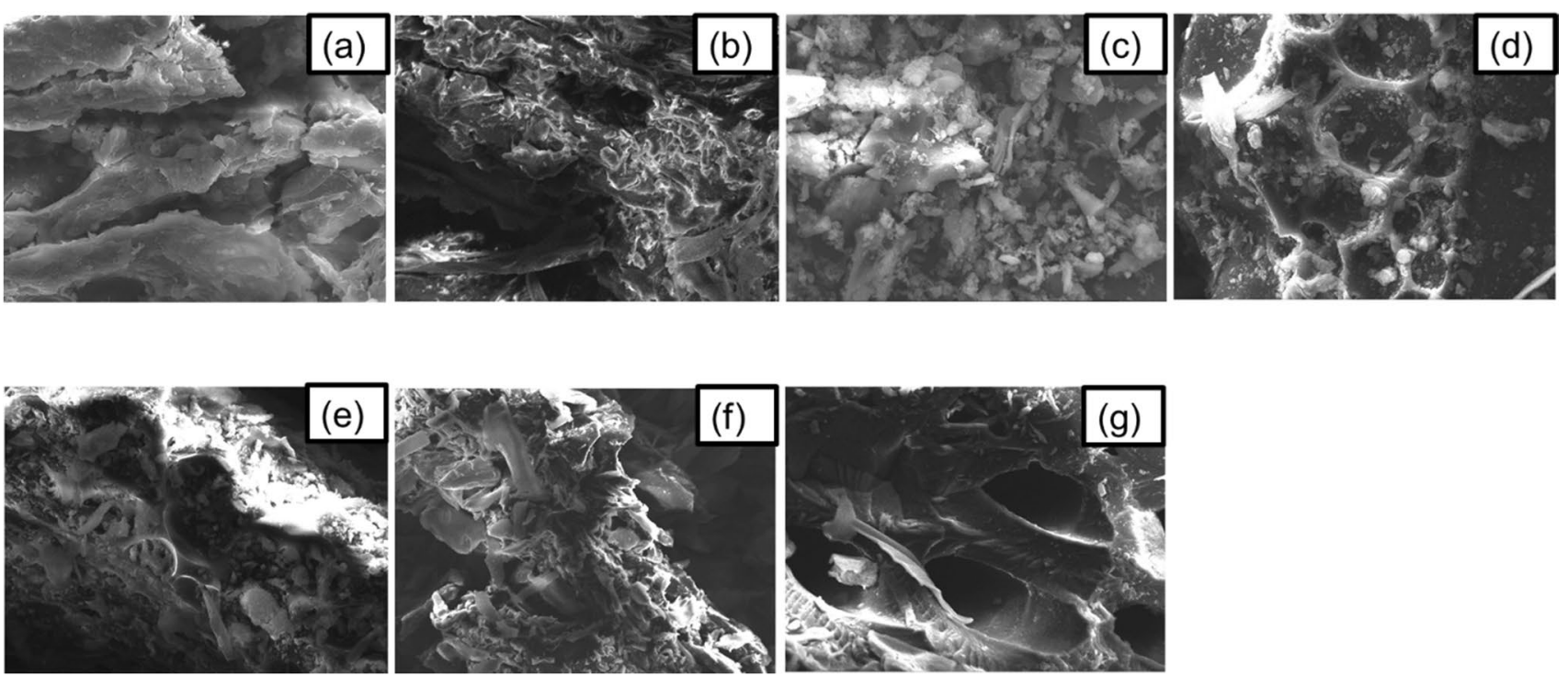

Fig. 2 Captured SEM image at×2000 magnification: a raw DM, b raw JL, c 100 wt.\% DM, d 25 wt.\% JL, e 50 wt. \% JL, f 75 wt.\% JL and g 100 wt.\% JL

Fig. 3 specific surface area, total pore volume and average pore diameter

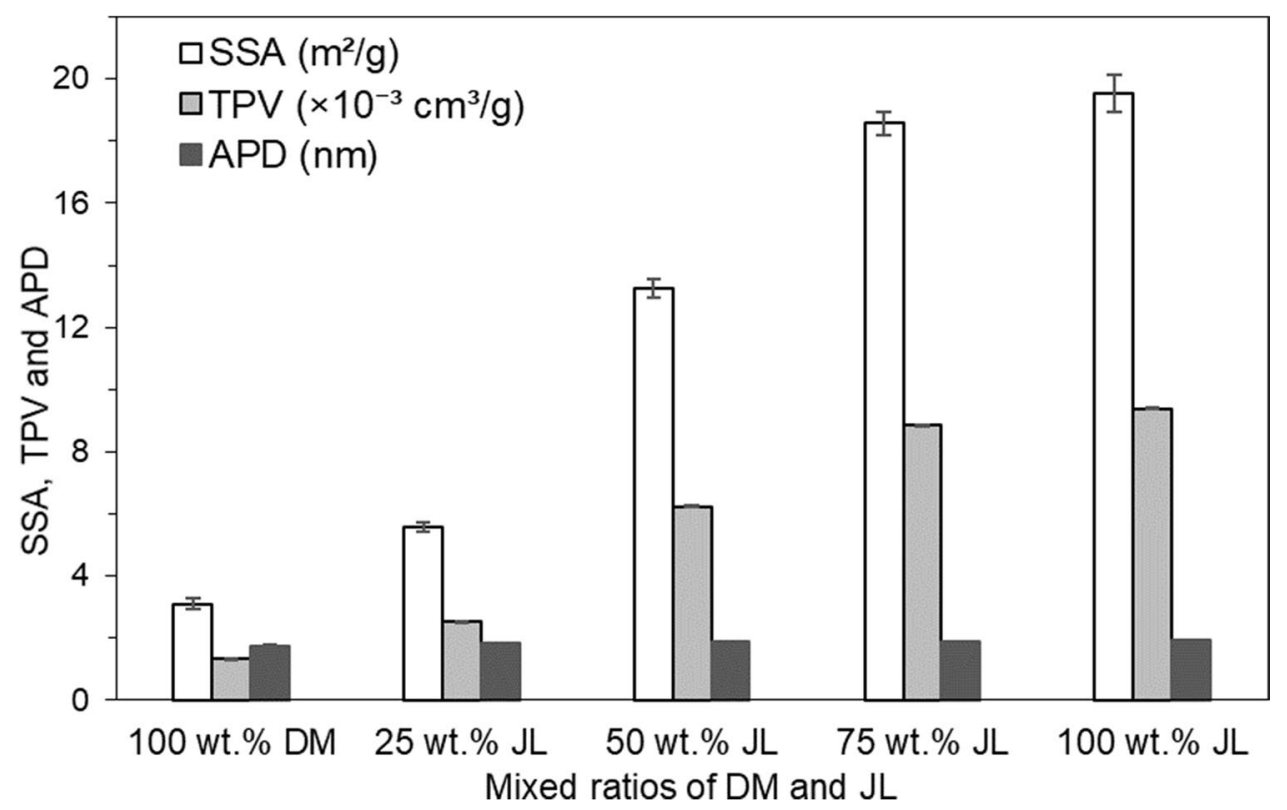

may have contributed to the blockage and reduction of the porous pores in the hydrochars from the co-HTC process. This could be said to conform with the results of the SSA and TPV. One of the possible reasons to the blockage of the porous pores could be due to the high ash content of the DM. It is well known that organic acids are formed because of the hydrolysis of biomass during HTC and catalyse the release of inorganic elements [34]. Given the low ash content of the JL (Table 1), this effect may not be noticeable as opposed to the co-HTC process with ash contribution by the DM. Another probable reason could be attributed to the adsorption of nitrogen from decomposed protein in DM on the porous surface of the hydrochars from the co-HTC process [10].

\subsection{Specific surface area, total pore volume and average pore diameter}

To further verify the effect of the co-HTC process on the hydrochar morphology, the SSA, TPV and APD of the produced hydrochars were determined and depicted in Fig. 3. The 100 wt.\% JL exhibited a high SSA and TPV likely due to its low ash content as previously stated. As a result of the co-HTC with a high ash DM, the SSA and TPV significantly 
declined. Hence, the implication would be that co-HTC of $\mathrm{JL}$ with a higher mass ratio of the DM may not facilitate high nutrient retention and better habitat for microbes if used for soil amendment [43]. Also, the surface may need some pretreatment such as surface activation to increase its ability to adsorb contaminants from aqueous solutions [34]. However, the APD of all the hydrochars were nearly the same value.

\subsection{Changes in the functional groups of the hydrochar after HTC and co-HTC}

To illustrate changes in the functional groups on the surface of the hydrochars at the different mixed ratio after co-HTC, FTIR analysis was performed and the result is presented in Fig. 4. The broad band of spectra observed between 3100 and $3500 \mathrm{~cm}^{-1}$ is ascribed to the stretching vibration of the $-\mathrm{OH}$ in the hydroxyl or carboxyl group [10, 12, 24]. Reduced peak intensities of the hydrochars between 3100 and $3500 \mathrm{~cm}^{-1}$ showed intensive dehydration reaction occurred during conversion at $260{ }^{\circ} \mathrm{C}[12,17,24,44]$. The stretching vibrations between 2870 and $2940 \mathrm{~cm}^{-1}$ showed the aliphatic $-\mathrm{CH}_{\mathrm{x}}$ group [12]. The stretching vibrations around $1645 \mathrm{~cm}^{-1}$ indicate the ketone and amide group of $-\mathrm{C}=\mathrm{O}$ [12]. The peaks became slightly broader by coHTC with the DM which showed that decarboxylation was promoted [12]. The sharp peaks observed between 2167 and $2297 \mathrm{~cm}^{-1}$ is ascribed to the $-\mathrm{C} \equiv \mathrm{N}$ of the nitriles group [45]. The $100 \mathrm{wt} . \% \mathrm{JL}$ showed no peek at this stretching vibration which indicates undetectable spectra of the $-\mathrm{C} \equiv \mathrm{N}$ functional group. This could be related to the low nitrogen content of the JL (Table 1). However, co-HTC with $\mathrm{DM}$ altered its functional group as peaks appeared thereafter. This revealed that there may have been a chemical interaction between the two biomasses and may have led to the formation of compounds linked to the $-\mathrm{C} \equiv \mathrm{N}$ functional group. This could also be related to the captured SEM image (Figs. 2d-f) which showed no porous holes after the co-HTC process. The absence of peaks around $1735 \mathrm{~cm}^{-1}$ showed that hemicellulose was decomposed after the HTC and coHTC processes at $260{ }^{\circ} \mathrm{C}$. Certainly, Reza et al. [10] reported the absence of a peak at $1735 \mathrm{~cm}^{-1}$ after HTC pre-treatment of cow manure at $260{ }^{\circ} \mathrm{C}$ and was ascribed to the decomposition of hemicellulose. It is well known that hemicellulose decomposes completely after HTC pre-treatment of biomass at a temperature of $220^{\circ} \mathrm{C}$ [46]. The finger prints vibrations between 1200 and $1460 \mathrm{~cm}^{-1}$ are ascribed to the degradation of lignocellulosic components [17, 24]. The sharp peaks observed at $1540 \mathrm{~cm}^{-1}$ were ascribed to increased lignin concentration [10]. Certainly, Reza et al. [10] reported that the lignin concentration in cow manure increased after HTC pre-treatment at $260{ }^{\circ} \mathrm{C}$. The intense unstable vibrations between 870 and $1200 \mathrm{~cm}^{-1}$ are ascribed to the presence of mineral components or ash $[24,47,48]$. The sharp peaks observed for $100 \mathrm{wt} . \% \mathrm{DM}$ and $25 \mathrm{wt}$ \% JL could be due to the high ash composition (Table 1) at these mixed ratios. The peaks around $750 \mathrm{~cm}^{-1}$ suggests increased aromaticity of the hydrochars $[44,45]$.

\subsection{Thermal behaviour and characteristic combustion parameters}

Figure 5 illustrates the mass loss (TG) and the derivative thermogravimetry (DTG) curves for the raw samples and the hydrochars at a heating rate of $10^{\circ} \mathrm{C} / \mathrm{min}$ (results for the other heating rates are shown in S2 to S4). Some characteristic combustion temperatures were subsequently determined
Fig. 4 the FTIR spectra of the hydrochars

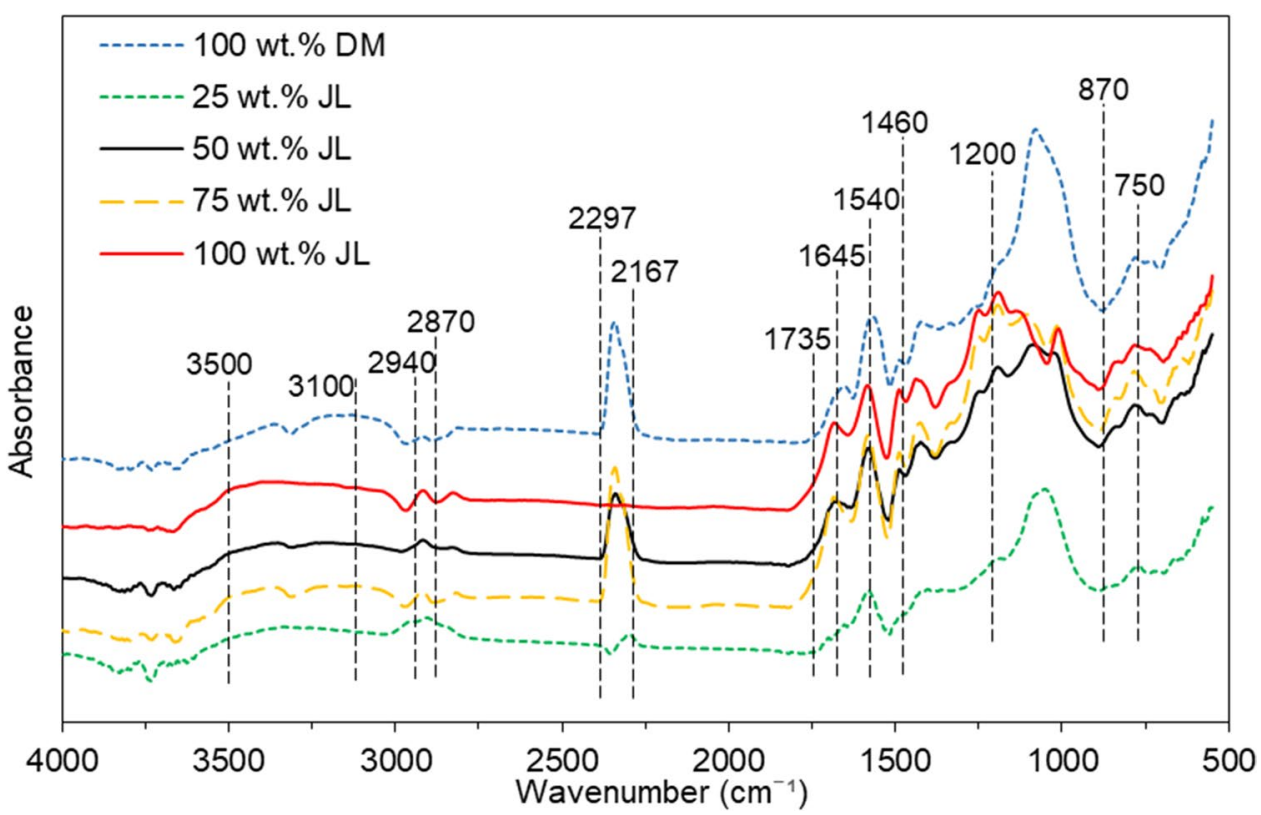



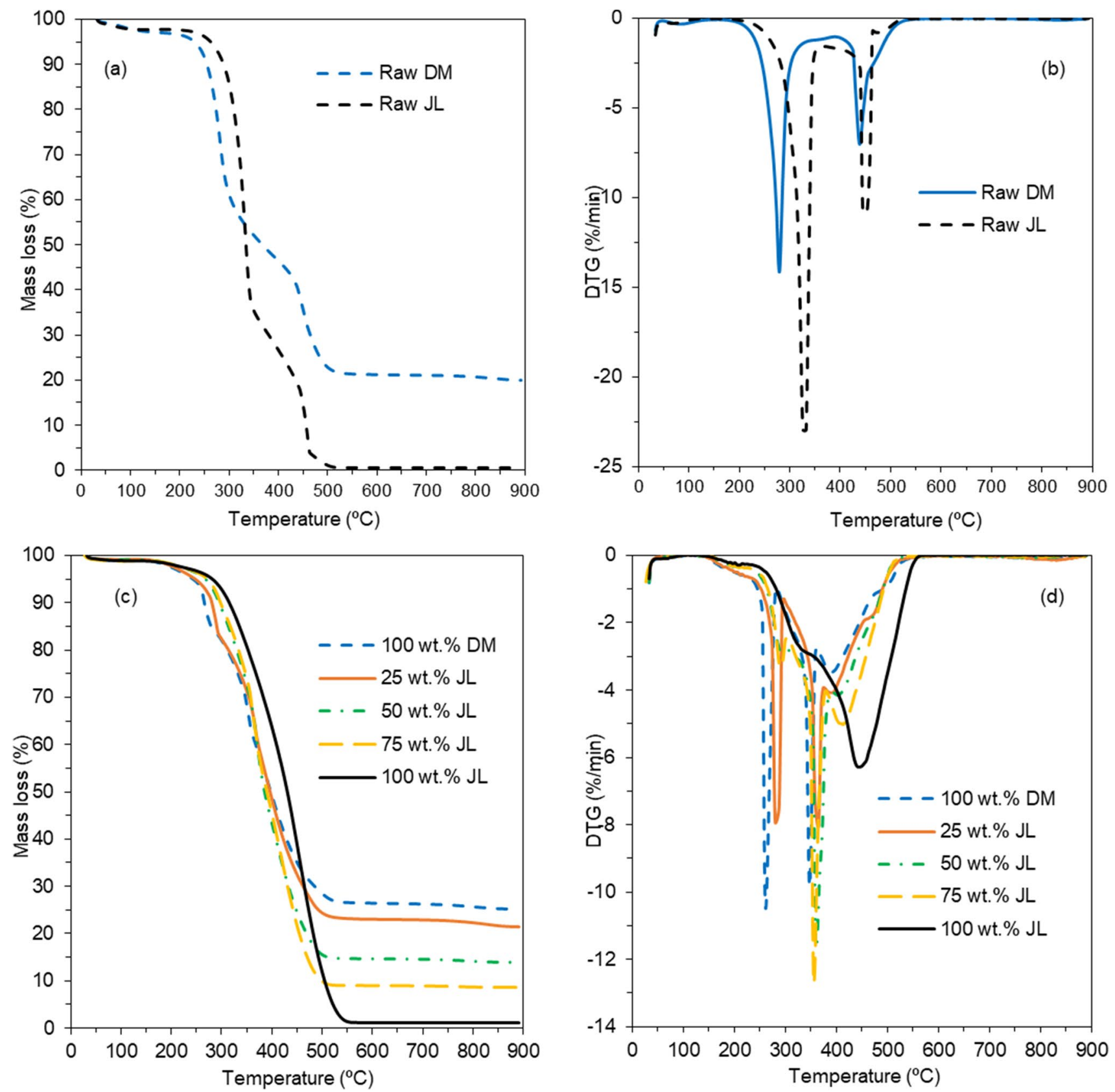

Fig. 5 a The mass loss for the raw samples. b DTG for raw samples. $\mathbf{c}$ The mass loss for the hydrochars. $\mathbf{d}$ DTG for the hydrochars at a heating rate of $10^{\circ} \mathrm{C} / \mathrm{min}$

from the curves at the heating rate of $10{ }^{\circ} \mathrm{C} / \mathrm{min}$. The raw $\mathrm{JL}$ exhibited a further mass loss and DTG peaks than the DM (Fig. 5a and b). The further mass loss of the raw JL may have resulted from its higher VM and lower ash content (Table 1). Figures $5 \mathrm{c}$ and $\mathrm{d}$ show the TG and DTG for the hydrochars. Figure $5 \mathrm{~d}$ reveals four distinctive peaks corresponding to the loss of moisture $\left(50-200{ }^{\circ} \mathrm{C}\right), \mathrm{VM}$ between 200 and $300{ }^{\circ} \mathrm{C}$, organic matter of complex chemical structure, such as lignin combustion phase $\left(300-400^{\circ} \mathrm{C}\right)$, char combustion $\left(400-600{ }^{\circ} \mathrm{C}\right)$ respectively $[3,44]$.
Table 2 depicts the characteristic temperatures, combustion parameters and performance of the hydrochars. The $\mathrm{I}_{\mathrm{T}}$ is an important characteristic temperature to determine the probability of fire or explosion of a solid biofuel during storage and transportation [3]. A higher $\mathrm{I}_{\mathrm{T}}$ is a desirable property of solid biofuel which means the difficulty of ignition, thus reduces the risk of fire or explosion [12]. The $\mathrm{I}_{\mathrm{T}}$ of hydrochar is expected to change due to the changes in properties caused by hydrolysis, decarboxylation, dehydration and aromatisation reactions during conversion. The hydrochar blend ratio 
Table 2 Characteristic temperatures, combustion parameters and performance at $10{ }^{\circ} \mathrm{C} / \mathrm{min}$

\begin{tabular}{lcclcccccc}
\hline Sample & $\mathrm{I}_{\mathrm{T}}\left({ }^{\circ} \mathrm{C}\right)$ & $\begin{array}{c}\mathrm{DTG}_{\max } \\
(\% / \mathrm{min} .)\end{array}$ & $\mathrm{DTG}_{\mathrm{av}}(\% / \mathrm{min})$. & $\mathrm{B}_{\mathrm{T}}\left({ }^{\circ} \mathrm{C}\right)$ & $\mathrm{B}_{\mathrm{t}}(\mathrm{min})$. & $\mathrm{T}_{\mathrm{m}}\left({ }^{\circ} \mathrm{C}\right)$ & $\mathrm{R}_{\mathrm{m}}(\%)$ & $\begin{array}{c}\mathrm{CCI}\left(10^{-7 \times}\right. \\
\left.\mathrm{min}^{-2 \times} \mathrm{C}^{-3}\right)\end{array}$ & $\begin{array}{l}\mathrm{CSI}\left(10^{4 \times}\right. \\
\left.\mathrm{min}^{-1 \times} \mathrm{C}^{-2}\right)\end{array}$ \\
\hline Raw DM & 234.4 & 14.2 & 0.91 & 534.5 & 50.9 & 283.2 & 19.9 & 4.4 & 1.8 \\
Raw JL & 268.0 & 22.9 & 1.13 & 515.5 & 48.6 & 322.0 & 0.61 & 6.9 & 2.3 \\
100wt.\% DM & 239.3 & 10.4 & 0.85 & 513.3 & 48.6 & 259.9 & 25.1 & 3.0 & 1.4 \\
25wt.\% JL & 263.3 & 8.0 & 0.89 & 508.5 & 48.2 & 364.5 & 21.4 & 2.0 & 7.2 \\
50wt.\% JL & 273.4 & 11.5 & 0.98 & 508.5 & 48.2 & 359.4 & 13.9 & 2.9 & 1.0 \\
75wt.\% JL & 272.9 & 12.7 & 1.04 & 504.8 & 47.7 & 356.3 & 8.7 & 3.5 & 1.1 \\
100wt.\% JL & 316.2 & 6.3 & 1.13 & 552.9 & 52.7 & 444.5 & 1.2 & 1.3 & 0.4 \\
\hline
\end{tabular}

of 50 wt.\% JL exhibited a slightly higher $\mathrm{I}_{\mathrm{T}}$ after the co-HTC process probably due to its lower VM (Table 1). However, the $\mathrm{I}_{\mathrm{T}}$ of the $100 \mathrm{wt} \% \mathrm{JL}$ was higher than those of the other hydrochars despite having a relatively higher VM. Certainly, He et al. [12] reported a similar observation where the $I_{T}$ of the hydrochar from rice straws was higher than that of the co-HTC process with a sewage sludge despite its higher $\mathrm{VM}$ of $42.7 \%$. One of the probable reasons for the higher $\mathrm{I}_{\mathrm{T}}$ of the $100 \mathrm{wt} \%$ JL could be its distinct feedstock properties (being a woody biomass that is expected to be richer in lignocellulosic components) which does not contain the DM like the other samples. It is also clear from the FTIR result in Fig. 3 that the $100 \mathrm{wt}$ \% JL did not show a peak for the $-\mathrm{C} \equiv \mathrm{N}$ functional group which may probably have reduced its higher $\mathrm{I}_{\mathrm{T}}$ and thermal stability. Indeed, Venna et al. [44] reported that the presence of degraded substances from protein in hydrochar could decrease its $\mathrm{I}_{\mathrm{T}}$ and thermal stability. However, the higher $\mathrm{I}_{\mathrm{T}}$ of the $100 \mathrm{wt} . \% \mathrm{JL}$ showed that it is more thermally stable and will be safer than the other hydrochars during handling, storage, and transportation $[12,49]$.

The $\mathrm{B}_{\mathrm{T}}$ is also a desirable property of solid biofuel; a high $\mathrm{B}_{\mathrm{T}}$ implies a longer combustion process [12]. The blend ratio of 75 wt.\% JL exhibited the lowest $\mathrm{B}_{\mathrm{T}}$ of $504.8{ }^{\circ} \mathrm{C}$ which corresponds to its lowest $\mathrm{B}_{\mathrm{t}}$ of $47.7 \mathrm{~min}$ compared to the other hydrochars from the co-HTC process. A possible reason could be its lower ash content or $\mathrm{R}_{\mathrm{m}}$ (Tables 1 and 2) compared to the other hydrochars from the co-HTC process. It was reported that inorganics in the ash can cause a decreased combustion reactivity of a solid biofuel [12]. Moreover, combustion is a complex reaction process and hence, different feedstocks have different combustion behaviour. In contrast, the highest $\mathrm{B}_{\mathrm{T}}$ of $552.9^{\circ} \mathrm{C}$ was observed for the 100 wt.\% JL despite its low ash content. The observed $\mathrm{B}_{\mathrm{T}}$ could also be related to the feedstock composition of the 100 wt.\% JL as earlier explained. Moreover, this observation is also similar to the study by He et al. [12] where the $\mathrm{B}_{\mathrm{T}}$ of the hydrochar produced from orange peels was higher than those of the co-HTC process with sewage sludge despite its lower ash content of $1.97 \%$. As for the $\mathrm{T}_{\mathrm{m}}$, a closely similar trend to the $\mathrm{B}_{\mathrm{T}}$ was observed. The $\mathrm{R}_{\mathrm{m}}$ after combustion of raw feedstocks and the hydrochars are also shown in Table 2. A noticeable reduction in the $\mathrm{R}_{\mathrm{m}}$ of the hydrochars was observed as the wt.\% of JL was increased and followed a similar trend as the ash content (Table 1) determined using a furnace.

The CCI and CSI are also useful indicators to evaluate the combustion performance of a solid biofuel. The higher values of CCI and CSI indicate improved combustion performance and stability. It should be noted that these indices are dependent on the $\mathrm{I}_{\mathrm{T}}, \mathrm{T}_{\mathrm{m}}, \mathrm{DTG}_{\mathrm{max}}, \mathrm{DTG}_{\mathrm{av}}$ and $\mathrm{B}_{\mathrm{T}}$ parameters. The CCI and CSI were lowered after the HTC process possibly owing to the reduced VM contents [12]. The decreased CCI and CSI values mean a decrease in the combustion performance and stability of hydrochars after HTC pre-treatment. However, this could be an advantage during usage for combustion because heat loss could be reduced due to unstable flame that may result from high VM [12]. The lowest CCI and CSI values of 1.3 and 0.4 were determined for the $100 \mathrm{wt} \% \mathrm{JL}$ due to its higher $\mathrm{I}_{\mathrm{T}}, \mathrm{T}_{\mathrm{m}}$ and $\mathrm{B}_{\mathrm{T}}$ which showed a decreased combustion performance [50] compared to the other hydrochars. Interestingly, the combustion performance of the co-HTC process improved at $75 \mathrm{wt} \% \mathrm{JL}$ and hence a positive synergy.

\subsection{Activation energy of the raw samples and the hydrochars}

Figures 6 and 7 show the plots of $\ln \beta$ and $\ln \left(\frac{\beta}{T^{2}}\right)$ versus $1 / \mathrm{T}$ at the heating rates of $5,10,15$ and $20{ }^{\circ} \mathrm{C} / \mathrm{min}$ for the $\mathrm{FWO}$ and KAS models, respectively. The slopes and the intercepts at each $\alpha$ of 0.1 to 0.8 from simple regression line equations or plots were used to determine the activation energies of the samples (S5 and S6). Tables 3 and 4 show the activation energies and their respective coefficients of determinations $\left(\mathrm{R}^{2}\right)$ for the raw samples and the hydrochars from the HTC and the co-HTC processes, respectively. The average 

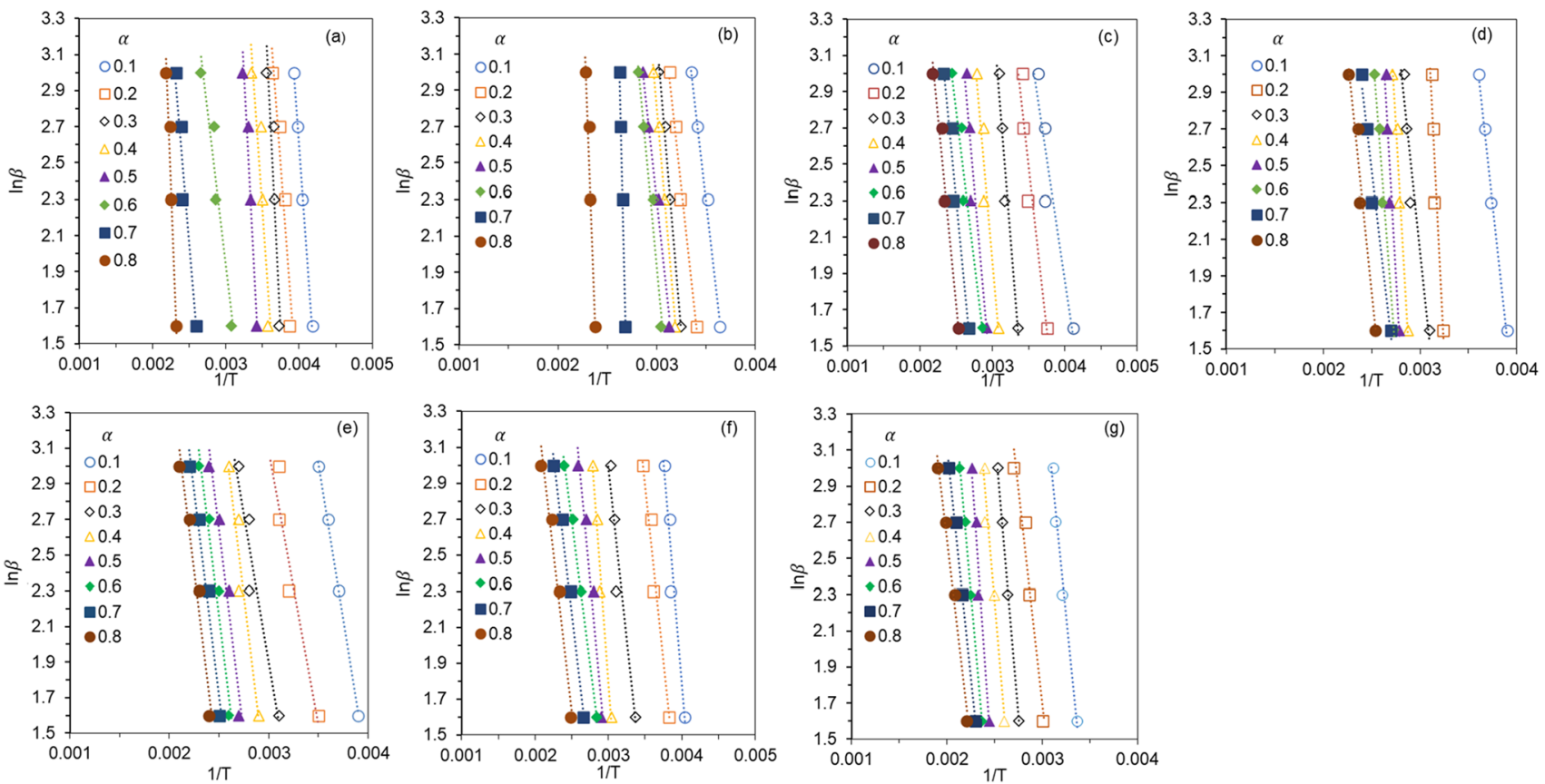

Fig. 6 The kinetic plots for the FWO: a raw DM, b raw JL, c 25\% JL, d 50\% JL, e 75\% JL, f 100\% DM, g 100\% JL
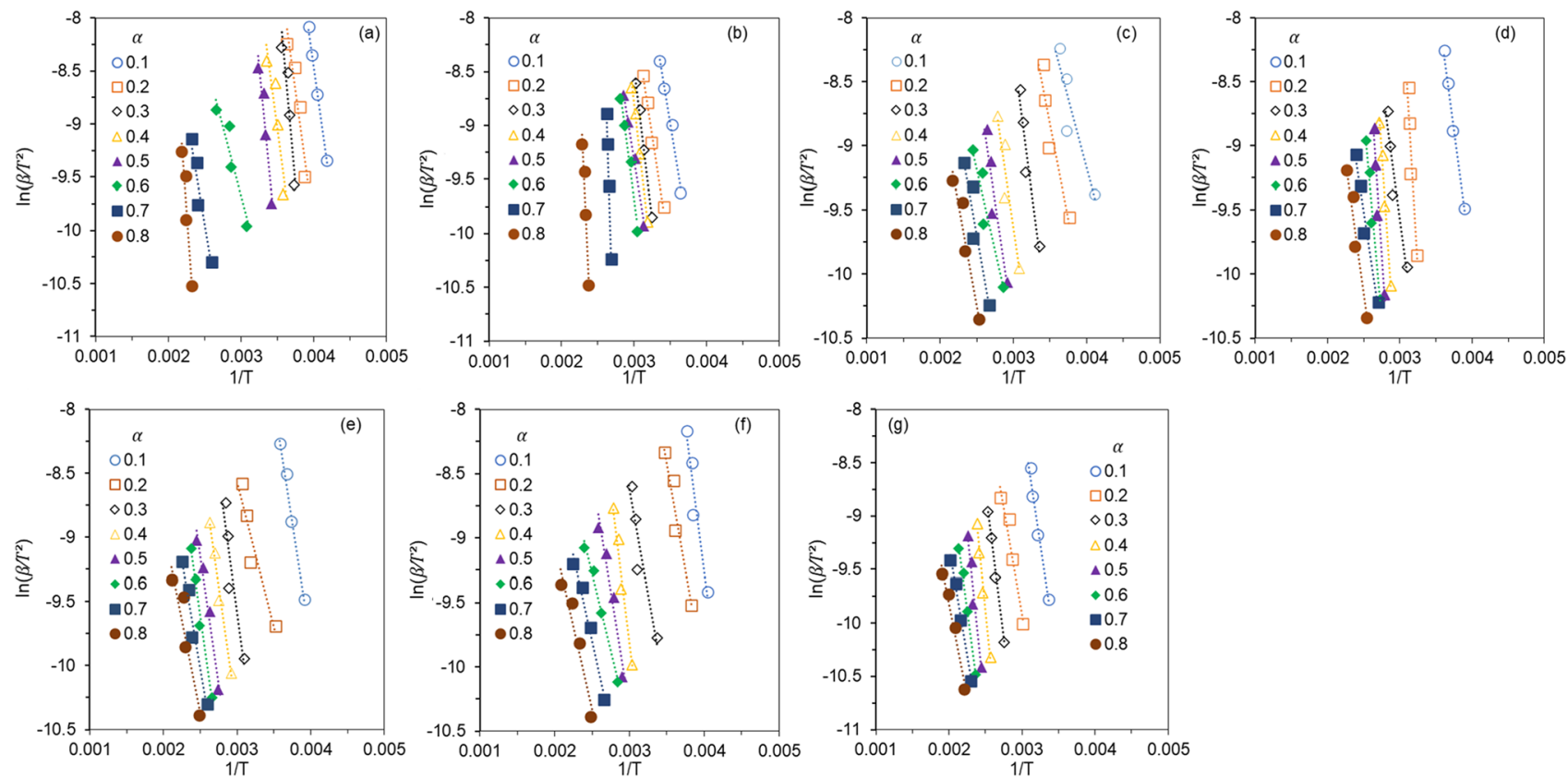

Fig. 7 The kinetic plots for the KAS: a raw DM, b raw JL, c 25 wt.\% JL, d 50 wt.\% JL, e 75 wt.\% JL, f 100 wt.\% DM, g 100 wt.\% JL

determined activation energy values of 72.1 and $69.7 \mathrm{~kJ} \mathrm{~mol}^{-1}$ for the raw JL by the FWO and KAS models were higher than 50.5 and $47.3 \mathrm{~kJ} \mathrm{~mol}^{-1}$ for the raw DM. This means that more energy could be required to break the bonds in the biomass matrix to initiate the combustion process of the raw JL than the raw DM [3,50], which successfully explained the higher ignition temperature of the raw JL than the raw DM (Table 2). The average activation energies of the hydrochars from the HTC process (Table 3) decreased for the FWO and KAS models. The decreased activation is reported to be partly caused by the hydrochar properties such as highly amorphous carbonaceous structure 
Table 3 Activation energies for the raw samples and hydrochars from the HTC process at $10{ }^{\circ} \mathrm{C} /$ $\min$

\begin{tabular}{|c|c|c|c|c|c|c|c|}
\hline \multirow[t]{2}{*}{ Sample } & \multirow[t]{2}{*}{$\alpha$} & \multicolumn{2}{|l|}{ FWO } & \multirow[t]{2}{*}{ Sample } & \multirow[t]{2}{*}{$\alpha$} & \multicolumn{2}{|l|}{ KAS } \\
\hline & & $E_{a}\left(\mathrm{~kJ} \mathrm{~mol}^{-1}\right)$ & $R^{2}$ & & & $E_{a}\left(\mathrm{~kJ} \mathrm{~mol}^{-1}\right)$ & $R^{2}$ \\
\hline \multirow[t]{9}{*}{ Raw DM } & 0.1 & 43.9 & 0.995 & \multirow[t]{9}{*}{ Raw DM } & 0.1 & 41.8 & 0.995 \\
\hline & 0.2 & 43.6 & 0.896 & & 0.2 & 41.1 & 0.872 \\
\hline & 0.3 & 64.3 & 0.861 & & 0.3 & 62.4 & 0.838 \\
\hline & 0.4 & 46.4 & 0.830 & & 0.4 & 43.5 & 0.792 \\
\hline & 0.5 & 60.5 & 0.943 & & 0.5 & 58.1 & 0.929 \\
\hline & 0.6 & 26.7 & 0.930 & & 0.6 & 22.0 & 0.886 \\
\hline & 0.7 & 39.4 & 0.939 & & 0.7 & 34.3 & 0.913 \\
\hline & 0.8 & 79.4 & 0.918 & & 0.8 & 75.3 & 0.898 \\
\hline & Average & 50.5 & 0.914 & & Average & 47.3 & 0.890 \\
\hline \multirow[t]{9}{*}{ Raw JL } & 0.1 & 37.4 & 0.989 & \multirow[t]{9}{*}{ Raw JL } & 0.1 & 34.3 & 0.987 \\
\hline & 0.2 & 39.8 & 0.986 & & 0.2 & 36.5 & 0.981 \\
\hline & 0.3 & 50.4 & 0.995 & & 0.3 & 47.3 & 0.992 \\
\hline & 0.4 & 51.1 & 0.955 & & 0.4 & 47.9 & 0.992 \\
\hline & 0.5 & 39.9 & 0.987 & & 0.5 & 36.1 & 0.983 \\
\hline & 0.6 & 45.8 & 0.971 & & 0.6 & 42.2 & 0.963 \\
\hline & 0.7 & 192.5 & 0.998 & & 0.7 & 194.9 & 0.998 \\
\hline & 0.8 & 120.1 & 0.958 & & 0.8 & 118.1 & 0.949 \\
\hline & Average & 72.1 & 0.979 & & Average & 69.7 & 0.981 \\
\hline \multirow[t]{9}{*}{100 wt.\% DM } & 0.1 & 39.4 & 0.928 & \multirow[t]{9}{*}{100 wt.\% DM } & 0.1 & 36.9 & 0.909 \\
\hline & 0.2 & 31.1 & 0.959 & & 0.2 & 27.9 & 0.942 \\
\hline & 0.3 & 30.6 & 0.903 & & 0.3 & 26.7 & 0.868 \\
\hline & 0.4 & 43.9 & 0.975 & & 0.4 & 40.2 & 0.966 \\
\hline & 0.5 & 34.7 & 0.959 & & 0.5 & 30.1 & 0.938 \\
\hline & 0.6 & 25.2 & 0.994 & & 0.6 & 19.9 & 0.986 \\
\hline & 0.7 & 27.3 & 0.989 & & 0.7 & 21.7 & 0.977 \\
\hline & 0.8 & 27.6 & 0.963 & & 0.8 & 21.5 & 0.928 \\
\hline & Average & 32.5 & 0.959 & & Average & 28.1 & 0.939 \\
\hline \multirow[t]{9}{*}{100 wt.\% JL } & 0.1 & 42.4 & 0.979 & \multirow[t]{9}{*}{100 wt.\% JL } & 0.1 & 39.1 & 0.975 \\
\hline & 0.2 & 37.5 & 0.954 & & 0.2 & 33.2 & 0.933 \\
\hline & 0.3 & 50.4 & 0.996 & & 0.3 & 46.3 & 0.994 \\
\hline & 0.4 & 48.9 & 0.955 & & 0.4 & 56.9 & 0.979 \\
\hline & 0.5 & 59.8 & 0.952 & & 0.5 & 55.4 & 0.939 \\
\hline & 0.6 & 47.8 & 0.995 & & 0.6 & 42.5 & 0.992 \\
\hline & 0.7 & 39.9 & 0.995 & & 0.7 & 33.9 & 0.989 \\
\hline & 0.8 & 35.6 & 0.986 & & 0.8 & 29.0 & 0.975 \\
\hline & Average & 45.3 & 0.977 & & Average & 42.1 & 0.972 \\
\hline
\end{tabular}

and high surface area [3]. As for the co-HTC process, the average activation energies of the hydrochars (Table 4) also decreased except at $50 \mathrm{wt}$.\% JL for the FWO and KAS models. The hydrochar of $50 \mathrm{wt} . \% \mathrm{JL}$ revealed a higher determined activation energy value of 55.2 and $51.7 \mathrm{~kJ} \mathrm{~mol}^{-1}$ for the FWO and KAS models. This suggests that it could be more resistant to thermal decomposition than the other hydrochars [3]. One of the probable reasons could be that, at $50 \mathrm{wt} \% \mathrm{JL}$ (equal wt.\% of the JL and DM), there was a higher possibility for more equilibrium in chemical interaction between the feedstocks during conversion. The equilibrium in interaction during conversion may have enhanced polymerisation and aromatisation reactions which may have led to the formation of a more thermal resistant hydrochar, resulting in higher activation energy.

\subsection{Thermodynamic analysis}

The thermodynamic parameters of thermal decomposition are of great importance to properly design a combustion equipment $[3,30]$. Table 5 shows the thermodynamic properties of activation for the raw samples and the hydrochars. In general, the value of $A<10^{9} \mathrm{~s}^{-1}$ shows a surface reaction in most cases [37]. The average value of $A$ from Table 5 
Table 4 Activation energies for the hydrochar from the co-HTC process at $10^{\circ} \mathrm{C} / \mathrm{min}$

\begin{tabular}{|c|c|c|c|c|c|c|c|}
\hline \multirow[t]{2}{*}{ Sample } & \multirow[t]{2}{*}{$\alpha$} & \multicolumn{2}{|l|}{ FWO } & \multirow[t]{2}{*}{ Sample } & \multirow[t]{2}{*}{$\alpha$} & \multicolumn{2}{|l|}{ KAS } \\
\hline & & $E_{a}\left(\mathrm{~kJ} \mathrm{~mol}^{-1}\right)$ & $R^{2}$ & & & $E_{a}\left(\mathrm{~kJ} \mathrm{~mol}^{-1}\right)$ & $R^{2}$ \\
\hline \multirow[t]{9}{*}{25 wt.\% JL } & 0.1 & 21.1 & 0.883 & \multirow[t]{9}{*}{25 wt. $\%$ JL } & 0.1 & 17.7 & 0.829 \\
\hline & 0.2 & 28.1 & 0.903 & & 0.2 & 24.7 & 0.870 \\
\hline & 0.3 & 40.4 & 0.941 & & 0.3 & 37.0 & 0.925 \\
\hline & 0.4 & 36.4 & 0.911 & & 0.4 & 32.3 & 0.877 \\
\hline & 0.5 & 37.1 & 0.898 & & 0.5 & 32.7 & 0.862 \\
\hline & 0.6 & 26.5 & 0.943 & & 0.6 & 21.4 & 0.906 \\
\hline & 0.7 & 32.2 & 0.939 & & 0.7 & 26.9 & 0.903 \\
\hline & 0.8 & 31.8 & 0.959 & & 0.8 & 26.1 & 0.931 \\
\hline & Average & 31.7 & 0.922 & & Average & 27.4 & 0.888 \\
\hline \multirow[t]{9}{*}{50 wt.\% JL } & 0.1 & 38.4 & 0.989 & \multirow[t]{9}{*}{50 wt. \% JL } & 0.1 & 35.7 & 0.987 \\
\hline & 0.2 & 84.6 & 0.908 & & 0.2 & 83.1 & 0.897 \\
\hline & 0.3 & 38.9 & 0.926 & & 0.3 & 35.1 & 0.905 \\
\hline & 0.4 & 70.7 & 0.969 & & 0.4 & 67.8 & 0.961 \\
\hline & 0.5 & 76.6 & 0.917 & & 0.5 & 73.9 & 0.906 \\
\hline & 0.6 & 55.9 & 0.974 & & 0.6 & 52.1 & 0.966 \\
\hline & 0.7 & 35.9 & 0.969 & & 0.7 & 30.9 & 0.957 \\
\hline & 0.8 & 40.4 & 0.954 & & 0.8 & 35.2 & 0.931 \\
\hline & Average & 55.2 & 0.951 & & Average & 51.7 & 0.939 \\
\hline \multirow[t]{9}{*}{75 wt.\% JL } & 0.1 & 27.9 & 0.998 & \multirow[t]{9}{*}{75 wt. $\%$ JL } & 0.1 & 31.4 & 0.987 \\
\hline & 0.2 & 24.3 & 0.921 & & 0.2 & 18.7 & 0.904 \\
\hline & 0.3 & 26.3 & 0.909 & & 0.3 & 35.7 & 0.859 \\
\hline & 0.4 & 36.6 & 0.926 & & 0.4 & 33.6 & 0.977 \\
\hline & 0.5 & 36.4 & 0.962 & & 0.5 & 33.8 & 0.971 \\
\hline & 0.6 & 36.4 & 0.962 & & 0.6 & 33.9 & 0.986 \\
\hline & 0.7 & 36.4 & 0.962 & & 0.7 & 27.4 & 0.962 \\
\hline & 0.8 & 36.4 & 0.962 & & 0.8 & 23.9 & 0.869 \\
\hline & Average & 32.6 & 0.950 & & Average & 29.8 & 0.939 \\
\hline
\end{tabular}

Table 5 Thermodynamic analysis values at $10{ }^{\circ} \mathrm{C} / \mathrm{min}$

\begin{tabular}{llllll}
\hline & Sample & $A\left(\mathrm{~s}^{-1}\right)$ & $\Delta G^{\ddagger}\left(\mathrm{kJ} \mathrm{mol}^{-1}\right)$ & $\Delta H^{\ddagger}\left(\mathrm{kJ} \mathrm{mol}^{-1}\right)$ & $\Delta S^{\ddagger}\left(\mathrm{J} \mathrm{mol}^{-1}\right)$ \\
\hline FWO & Raw DM & $3.09 \times 10^{5}$ & 131.2 & 45.6 & -153.9 \\
& Raw JL & $1.48 \times 10^{7}$ & 139.6 & 67.0 & -121.9 \\
& $100 \mathrm{DM}$ & $5.91 \times 10^{3}$ & 127.1 & 27.3 & -187.2 \\
& 25 wt.\% JL & $1.04 \times 10^{3}$ & 155.0 & 26.5 & -201.6 \\
& 50wt.\% JL & $1.69 \times 10^{5}$ & 150.7 & 49.9 & -159.4 \\
& 75wt.\% JL & $1.41 \times 10^{3}$ & 152.7 & 27.3 & -199.2 \\
\multirow{4}{*}{ KAS } & 100wt.\% JL & $5.91 \times 10^{3}$ & 174.5 & 39.6 & -187.9 \\
& Raw DM & $1.45 \times 10^{5}$ & 131.5 & 42.4 & -160.2 \\
& Raw JL & $8.69 \times 10^{6}$ & 139.8 & 64.6 & -126.2 \\
& 100 DM & $1.91 \times 10^{3}$ & 127.8 & 22.9 & -196.6 \\
& 25 wt.\% JL & $3.99 \times 10^{2}$ & 155.8 & 22.2 & -209.6 \\
& 50wt.\% JL & $8.25 \times 10^{4}$ & 151.1 & 46.5 & -165.3 \\
& 75 wt.\% JL & $7.59 \times 10^{2}$ & 153.2 & 24.5 & -204.4 \\
& 100wt.\% JL & $3.21 \times 10^{3}$ & 174.9 & 36.4 & -192.9 \\
\hline
\end{tabular}

varied from $10^{2}$ to $10^{7}$ for the FWO and KAS models. The values of $A$ suggested that complex reactions occurred during the thermal degradation process [3].
A positive value of $\Delta G^{\ddagger}$ for a process means it is nonspontaneous while a negative value means it is spontaneous 
$[3,30,37]$. A spontaneous process does not require external energy for initiation while a non-spontaneous process such as solid fuel combustion needs energy supply to initiate the process. The positive values of $\Delta G^{\ddagger}$ observed in Table 5 revealed that the thermal degradation of the samples was not a spontaneous process $[30,51]$. This means that energy must be supplied to initiate the combustion process of the raw samples and the hydrochars. The hydrochars from the co-HTC process have lower $\Delta G^{\ddagger}$ values than the $100 \mathrm{wt} . \%$ JL but higher $\Delta G^{\ddagger}$ values than for the 100 wt.\% DM. This suggests that the combustion process of the hydrochars from the co-HTC is more favored compared to the $100 \mathrm{wt} . \% \mathrm{JL}$ but less favored compared to the $100 \mathrm{wt} . \%$ DM [3].

The $\Delta H^{*}$ value is reported to be a better parameter for predicting the bond strength than the $E_{a}$ value [3]. The values of $\Delta H^{\ddagger}$ followed a similar trend like those of the average values of $E_{a}$ (Tables 3, 4 and 5). Moreover, it was also reported that if the difference between the value of $\Delta H^{\ddagger}$ and $E_{a}$ is small (in this case, the differences from Table 5 were $<6 \mathrm{~kJ} \mathrm{~mol}^{-1}$ ), then a low energy barrier would be needed to promote the formation of the activated complex of the sample [3, 51]. Lang et al. [3] also reported a similar trend $\left(<7 \mathrm{~kJ} \mathrm{~mol}^{-1}\right.$ between $\Delta H^{\ddagger}$ and $E_{a}$ values) from the combustion of hydrochar from the co-HTC process and concluded that a low energy barrier was needed. In addition, the positive $\Delta H^{\ddagger}$ values in Table 5 means endothermicity of the process which suggests that, to overcome the activation barrier, energy need to be supplied for the thermal degradation of the samples for both the FWO and KAS kinetic models [37]. The result showed that the raw JL needed a higher energy supply (67.0 and $\left.64.6 \mathrm{~kJ} \mathrm{~mol}^{-1}\right)$ to overcome the activation barrier to promote its transformation during combustion than the raw DM by both FWO and KAS models. For the HTC process, $100 \mathrm{wt}$.\% JL was the most difficult to proceed with its combustion process during transformation. As for the co-HTC process, $50 \mathrm{wt} \% \% \mathrm{JL}$ has the highest value of $\Delta H^{\ddagger}$ (49.9 and $46.5 \mathrm{~kJ} \mathrm{~mol}^{-1}$ ) which means that it is more difficult to initiate its combustion process to the transition state. The $25 \mathrm{wt} . \% \mathrm{JL}$ is the easiest to initiate its combustion process because it needs the lowest external energy supply to overcome the activation barrier and hence, accelerated combustion $\left(\Delta H^{\ddagger}=26.5 \mathrm{~kJ} \mathrm{~mol}^{-1}\right)$.

The value of $\Delta S^{\ddagger}$ for a process showed the degree of randomness or disorder of matter and energy in the system or process $[3,30,37]$. A high value of $\Delta S^{\ddagger}$ for a process or system implies that, it is in a state further from thermodynamic equilibrium, showing high reactivity $[3,30,37]$. Therefore, the sample with a higher value of $\Delta S^{\ddagger}$ required more energy to reduce the degree of disorder during transformation $[3,30]$. The low values of $\Delta S^{\ddagger}$ from Table 5 showed that the degree of disorder of matter was low during transformation. Results from this study in Table 5 showed that the degree of disorder decreased after the HTC and co-HTC processes (lower values than the raw samples). The lowest degree of randomness of -201.6 and $-209.6 \mathrm{~J} \mathrm{~mol}^{-1}$ were observed for $25 \mathrm{wt}$.\% $\mathrm{JL}$ which depicts lower reactivity during transformation by thermal degradation [30]. On the other hand, the $50 \mathrm{wt} . \%$ $\mathrm{JL}$ exhibits the highest degree of randomness $(-159.4$ and $-165.3 \mathrm{~J} \mathrm{~mol}^{-1}$ ) compared to the other hydrochars which suggests higher reactivity [3]. Low values of $\Delta S^{\dagger}$ $<0$ have been previously reported for the combustion of hydrochar from a co-HTC of corn stalks and swine manure [3]. In addition, since combustion is a complex process, it is obvious from Table 5 that the observed differences could be attributed to the material or feedstock composition and the method used to calculate the parameters.

\section{Conclusion}

Co-HTC was used to upgrade the solid biofuel quality indices of hydrochar from a blend of DM and JL. The produced hydrochars showed a promising property closed to the coal. An increase in the fixed carbon and carbon contents were observed as the mass ratio of the $\mathrm{JL}$ was increased. The blend of $75 \mathrm{wt} . \% \mathrm{JL}$ had the lowest ash content of $7.2 \pm 0.5 \%$ compared to the other blends. HHV of hydrochars improved remarkably to $26.4 \pm 0.02$ as the ratio of $\mathrm{JL}$ in the mixture was increased. The surface morphology and the surface functional groups were altered by the coHTC process. Surface characteristics such as SSA and TPV were also significantly increased after the co-HTC process. Thermal behaviour also revealed an improvement in combustion characteristics of the hydrochars. A decline in the combustion performance was observed after the HTC process but improved at $75 \mathrm{wt} . \% \mathrm{JL}$ after the co-HTC process. The kinetic analysis also revealed that the activation energy decreased after the HTC process but increased to a higher value at $50 \mathrm{wt} \% \mathrm{JL}$ after the co-HTC process. Therefore, hydrochar production by co-HTC of DM and JL has proved to be an effective and promising solid biofuel source.

Supplementary Information The online version contains supplementary material available at https://doi.org/10.1007/s13399-021-02045-0.

Acknowledgements The authors acknowledge the Instrumental Analyses Division of Hokkaido University, Japan, for performing elemental analyses of the samples. The authors also acknowledge Associate Professor Takahiro Nomura and Dr. Ade Kurniawan of the Centre for Advanced Research of Energy and Materials, Faculty of Engineering, Hokkaido University, Japan, for granting permission and assistance in performing the thermal analyses and surface morphology (SEM) in its laboratory.

Data availability Supplementary data is available. 
Code availability Not applicable.

\section{Declarations}

Conflict of interest The authors declare no competing interests.

Open Access This article is licensed under a Creative Commons Attribution 4.0 International License, which permits use, sharing, adaptation, distribution and reproduction in any medium or format, as long as you give appropriate credit to the original author(s) and the source, provide a link to the Creative Commons licence, and indicate if changes were made. The images or other third party material in this article are included in the article's Creative Commons licence, unless indicated otherwise in a credit line to the material. If material is not included in the article's Creative Commons licence and your intended use is not permitted by statutory regulation or exceeds the permitted use, you will need to obtain permission directly from the copyright holder. To view a copy of this licence, visit http://creativecommons.org/licenses/by/4.0/.

\section{References}

1. Martins F, Felgueiras C, Smitkova M, Caetano N 2019 Analysis of fossil fuel energy consumption and environmental impacts in European countries. Energies 12:964. https://doi.org/10.3390/ EN12060964

2. Kambo HS, Dutta A (2015) A comparative review of biochar and hydrochar in terms of production, physico-chemical properties and applications. Renew Sustain Energy Rev 45:359-378. https://doi. org/10.1016/j.rser.2015.01.050

3. Lang Q, Zhang B, Liu Z et al (2019) Co-hydrothermal carbonization of corn stalk and swine manure: Combustion behavior of hydrochar by thermogravimetric analysis. Biores Technol 271:7583. https://doi.org/10.1016/j.biortech.2018.09.100

4. Cárdenas-Aguiar E, Gascó G, Paz-Ferreiro J, Méndez A (2019) Thermogravimetric analysis and carbon stability of chars produced from slow pyrolysis and hydrothermal carbonization of manure waste. J Anal Appl Pyrol 140:434-443. https://doi.org/ 10.1016/J.JAAP.2019.04.026

5. Shimahata A Farghali M Fujii M 2020 Factors Influencing the Willingness of Dairy Farmers to Adopt Biogas Plants: A Case Study in Hokkaido, Japan Sustainability 127809 10.3390/ SU12187809

6. Wu K, Gao Y, Zhu G et al (2017) Characterization of dairy manure hydrochar and aqueous phase products generated by hydrothermal carbonization at different temperatures. J Anal Appl Pyrol 127:335-342. https://doi.org/10.1016/j.jaap.2017.07.017

7. Bach QV, Skreiberg O (2016) Upgrading biomass fuels via wet torrefaction: a review and comparison with dry torrefaction. Renew Sustain Energy Rev 54:665-677. https://doi.org/10.1016/J. RSER.2015.10.014

8. Font-Palma C (2019) Methods for the Treatment of Cattle Manure-A Review. C 5:27. https://doi.org/10.3390/c5020027

9. Gao Y, Liu Y, Zhu G et al (2018) Microwave-assisted hydrothermal carbonization of dairy manure: Chemical and structural properties of the products. Energy 165:662-672. https://doi.org/ 10.1016/j.energy.2018.09.185

10. Reza MT, Freitas A, Yang X et al (2016) Hydrothermal carbonization (HTC) of cow manure: Carbon and nitrogen distributions in HTC products. Environ Prog Sustainable Energy 35:1002-1011. https://doi.org/10.1002/EP.12312

11. Doshi V, Vuthaluru HB, Korbee R, Kiel JHA (2009) Development of a modeling approach to predict ash formation during co-firing of coal and biomass. Fuel Process Technol 90:1148-1156. https:// doi.org/10.1016/J.FUPROC.2009.05.019

12. He C, Zhang Z, Ge C et al (2019) Synergistic effect of hydrothermal co-carbonization of sewage sludge with fruit and agricultural wastes on hydrochar fuel quality and combustion behavior. Waste Manage 100:171-181. https://doi.org/10.1016/J.WASMAN.2019. 09.018

13. Lee J, Sohn D, Lee K, Park KY (2019) Solid fuel production through hydrothermal carbonization of sewage sludge and microalgae Chlorella sp. from wastewater treatment plant. Chemosphere 230:157-163. https://doi.org/10.1016/J.CHEMOSPHERE.2019. 05.066

14. Mazumder S, Saha P, Reza MT (2020) Co-hydrothermal carbonization of coal waste and food waste: fuel characteristics. Biomass Conversion and Biorefinery 2020:1-11. https://doi.org/10.1007/ S13399-020-00771-5

15 Liang M, Zhang K, Lei P et al (2019) (2019) Fuel properties and combustion kinetics of hydrochar derived from co-hydrothermal carbonization of tobacco residues and graphene oxide. Biomass Conversion and Biorefinery 10:189-201. https://doi. org/10.1007/S13399-019-00408-2

16. Bardhan M, Novera TM, Tabassum M et al (2021) Co-hydrothermal carbonization of different feedstocks to hydrochar as potential energy for the future world: a review. J Clean Prod 298:126734. https://doi.org/10.1016/J.JCLEPRO.2021.126734

17. Lang Q, Guo Y, Zheng Q et al (2018) Co-hydrothermal carbonization of lignocellulosic biomass and swine manure: Hydrochar properties and heavy metal transformation behavior. Biores Technol 266:242-248. https://doi.org/10.1016/J.BIORTECH. 2018.06.084

18. Itoh T, Fujiwara N, Iwabuchi K et al (2020) Effects of pyrolysis temperature and feedstock type on particulate matter emission characteristics during biochar combustion. Fuel Process Technol 204:106408. https://doi.org/10.1016/J.FUPROC.2020. 106408

19. Yuan X, He T, Cao H, Yuan Q (2017) Cattle manure pyrolysis process: kinetic and thermodynamic analysis with isoconversional methods. Renewable Energy 107:489-496. https://doi.org/10. 1016/J.RENENE.2017.02.026

20. Singh S, Sawarkar AN (2020) Thermal decomposition aspects and kinetics of pyrolysis of garlic stalk. https://doi.org/10.1080/15567 036.2020.1716891

21. Reza MT, Andert J, Wirth B et al (2014) Hydrothermal carbonization of biomass for energy and crop production. Applied Bioenergy 1:11-29. https://doi.org/10.2478/apbi-2014-0001

22. Funke A, Biofuels FZ, Biorefining B, and, (2010) undefined (2010) Hydrothermal carbonization of biomass: a summary and discussion of chemical mechanisms for process engineering. Wiley Online Library 4:160-177. https://doi.org/10.1002/bbb.198

23. Lu X, Yamauchi K, Phaiboonsilpa N (2009) Saka S (2009) Twostep hydrolysis of Japanese beech as treated by semi-flow hotcompressed water. Journal of Wood Science 55(5):367-375. https://doi.org/10.1007/S10086-009-1040-6

24. Zhang X, Zhang L, Li A (2017) Hydrothermal co-carbonization of sewage sludge and pinewood sawdust for nutrient-rich hydrochar production: Synergistic effects and products characterization. $\mathbf{J}$ Environ Manage 201:52-62. https://doi.org/10.1016/J.JENVM AN.2017.06.018

25. Itoh T, Iwabuchi K, Maemoku $\mathrm{N}$ et al (2019) A new torrefaction system employing spontaneous self-heating of livestock manure under elevated pressure. Waste Manage 85:66-72. https://doi.org/ 10.1016/j.wasman.2018.12.018

26. Mureddu M, Dessì F, Orsini A et al (2018) Air- and oxygen-blown characterization of coal and biomass by thermogravimetric analysis. Fuel 212:626-637. https://doi.org/10.1016/j.fuel.2017.10.005 
27. Parthasarathy P, Al-Ansari T, Mackey HR, McKay G (2021) Effect of heating rate on the pyrolysis of camel manure. Biomass Conversion and Biorefinery 2021:1-13. https://doi.org/10.1007/ S13399-021-01531-9

28. Chen X, Ma X, Peng X et al (2018) Conversion of sweet potato waste to solid fuel via hydrothermal carbonization. Biores Technol 249:900-907. https://doi.org/10.1016/J.BIORTECH.2017.10.096

29. Xie C, Liu J, Zhang X et al (2018) Co-combustion thermal conversion characteristics of textile dyeing sludge and pomelo peel using TGA and artificial neural networks. Appl Energy 212:786-795. https://doi.org/10.1016/j.apenergy.2017.12.084

30. Chen J, Wang Y, Lang X, et al Evaluation of agricultural residues pyrolysis under non-isothermal conditions: thermal behaviors, kinetics, and thermodynamics. Elsevier

31. Gao Y, Wang XH, Yang HP, Chen HP (2012) Characterization of products from hydrothermal treatments of cellulose. Energy 42:457-465. https://doi.org/10.1016/J.ENERGY.2012.03.023

32. He C, Giannis A, Wang JY (2013) Conversion of sewage sludge to clean solid fuel using hydrothermal carbonization: Hydrochar fuel characteristics and combustion behavior. Appl Energy 111:257266. https://doi.org/10.1016/j.apenergy.2013.04.084

33. Odeh AO (2015) Comprehensive conventional analysis of Southern Hemisphere coal chars of different ranks for fixed bed gasification

34. Fang J, Zhan L, Ok YS, Gao B (2018) Minireview of potential applications of hydrochar derived from hydrothermal carbonization of biomass. J Ind Eng Chem 57:15-21. https://doi.org/10. 1016/j.jiec.2017.08.026

35. Kim D, Lee K, Fuel KP (2014) undefined (2014) Hydrothermal carbonization of anaerobically digested sludge for solid fuel production and energy recovery. Elsevier 130:120-125. https://doi. org/10.1016/j.fuel.2014.04.030

36. Wang T, Zhai Y, Li H et al (2018) Co-hydrothermal carbonization of food waste-woody biomass blend towards biofuel pellets production. Biores Technol 267:371-377. https://doi.org/10.1016/J. BIORTECH.2018.07.059

37. Ma J, Luo H, Li Y et al (2019) Pyrolysis kinetics and thermodynamic parameters of the hydrochars derived from co-hydrothermal carbonization of sawdust and sewage sludge using thermogravimetric analysis. Biores Technol 282:133-141. https://doi.org/10. 1016/J.BIORTECH.2019.03.007

38. Shen Y, Yu S, Ge S et al (2017) Hydrothermal carbonization of medical wastes and lignocellulosic biomass for solid fuel production from lab-scale to pilot-scale. Elsevier 118:312-323. https:// doi.org/10.1016/j.energy.2016.12.047

39. Cuvilas CA, Kantarelis E, Yang W (2015) The impact of a mild sub-critical hydrothermal carbonization pretreatment on Umbila wood. A mass and energy balance perspective. Energies 8:21652175. https://doi.org/10.3390/en8032165

40. Zhao P, Shen Y, Ge S, Yoshikawa K (2014) Energy recycling from sewage sludge by producing solid biofuel with hydrothermal carbonization. Energy Convers Manage 78:815-821. https://doi. org/10.1016/J.ENCONMAN.2013.11.026
41. Zornoza R, Moreno-Barriga F, Acosta JA et al (2016) Stability, nutrient availability and hydrophobicity of biochars derived from manure, crop residues, and municipal solid waste for their use as soil amendments. Chemosphere 144:122-130. https://doi.org/10. 1016/J.CHEMOSPHERE.2015.08.046

42. Vassilev SV, Baxter D, Andersen LK, Vassileva CG (2010) An overview of the chemical composition of biomass. Fuel 89:913933. https://doi.org/10.1016/J.FUEL.2009.10.022

43. Piash MI, Iwabuchi K, Itoh T, Uemura K (2021) Release of essential plant nutrients from manure- and wood-based biochars. Geoderma 397:115100. https://doi.org/10.1016/j.geoderma.2021. 115100

44. Venna S, Sharma H, Reddy P et al (2021) Landfill leachate as an alternative moisture source for hydrothermal carbonization of municipal solid wastes to solid biofuels. Elsevier 320:124410. https://doi.org/10.1016/j.biortech.2020.124410

45. Infrared Tables (short summary of common absorption... - Google Scholar. https://scholar.google.com/scholar?hl=en\&as_sdt=0\% $2 \mathrm{C} 5 \& \mathrm{q}=$ Infrared + Tables $+\% 28$ short+summary+of +common + absorption+frequencies $\% 29$.+Course+Notes $\% 2 C+2620 \% 2 \mathrm{C}+$ $19+\& b t n G=$. Accessed 17 Aug 2021

46. Heidari M, Dutta A, Acharya B, Mahmud S (2019) A review of the current knowledge and challenges of hydrothermal carbonization for biomass conversion. J Energy Inst 92:1779-1799. https:// doi.org/10.1016/j.joei.2018.12.003

47. Xu ZX, Song H, Zhang S et al (2019) Co-hydrothermal carbonization of digested sewage sludge and cow dung biogas residue: Investigation of the reaction characteristics. Energy 187:115972. https://doi.org/10.1016/J.ENERGY.2019.115972

48. Zheng C, Ma X, Yao Z, Chen X (2019) The properties and combustion behaviors of hydrochars derived from co-hydrothermal carbonization of sewage sludge and food waste. Biores Technol 285:121347. https://doi.org/10.1016/J.BIORTECH.2019.121347

49. Zhuang X, Zhan H, Huang Y et al (2018) Conversion of industrial biowastes to clean solid fuels via hydrothermal carbonization (HTC): Upgrading mechanism in relation to coalification process and. Elsevier 267:17-29. https://doi.org/10.1016/j.biortech.2018. 07.002

50. Lang Q, Luo H, Li Yi et al (2019) Thermal behavior of hydrochar from co-hydrothermal carbonization of swine manure and sawdust: effect of process water recirculation. Sustainable Energy Fuels 3:2329-2336. https://doi.org/10.1039/C9SE00332K

51. Dhyani V, Kumar Awasthi M, Wang Q et al (2018) Effect of composting on the thermal decomposition behavior and kinetic parameters of pig manure-derived solid waste. Biores Technol 252:59-65. https://doi.org/10.1016/J.BIORTECH.2017.12.083

Publisher's note Springer Nature remains neutral with regard to jurisdictional claims in published maps and institutional affiliations. 